\title{
Autoclaving-Derived Surface Coating with In Vitro and In Vivo Antimicrobial and Antibiofilm Efficacies
}

\author{
Yajuan Su, Zelun Zhi, Qiang Gao, Meihua Xie, Meng Yu, Bo Lei, Peng Li,* and Peter X. Ma
}

Biomedical device-associated infections which engender severe threat to public health require feasible solutions. In this study, block copolymers consisting of antimicrobial, antifouling, and surface-tethering segments in one molecule are synthesized and grafted on polymeric substrates by a facile plasma/autoclave-assisted method. Hetero-bifunctional polyethylene glycol (PEG) with allyl and tosyl groups (APEG-OTs) is first prepared. PEGs with different molecular weights (1200 and $2400 \mathrm{Da}$ ) are employed. Polyhexamethylene guanidine (PHMG) which has excellent broad-spectrum antimicrobial activity and thermal/chemical stability, is conjugated with APEG-OTs to generate the block copolymer (APEG-PHMG). Allyl terminated PHMG (A-PHMG) without PEG segments is also synthesized by reacting PHMG with allyl glycidyl ether. The synthesized copolymers are thermal initiated by autoclaving and grafted on plasma pretreated silicone surface, forming permanently bonded bottlebrush-like coatings. Both A-PHMG and APEG $1200 / 2400^{-}$PHMG coatings exhibit potent antimicrobial activity against gram-positive/negative bacteria and fungus, whereas APEG $1200 / 2400^{-P H M G}$ coatings show superior antifouling activity and long-term reusability to A-PHMG coating. APEG $2400^{-}$ PHMG coating demonstrates the most effective in vitro antibiofilm and protein/platelet-resistant properties, as well as excellent hemo/biocompatibility. Furthermore, $\mathrm{APEG}_{2400}$ - $\mathrm{PHMG}$ greatly reduces the bacteria number with 5 -log reduction in a rodent subcutaneous infection model. This rationally designed dual-functional antimicrobial and antifouling coating has great potential in combating biomedical devices/implant-associated infections.

\section{Introduction}

With the development of modern medicine, biomedical devices and implants are used extensively in hospitals. Although these devices/implants save lives and improve the life quality of patients, they are also prone to microbial contamination. ${ }^{[1]}$ In a systematic review, more than half of biomedical devices were reported to harbor microbial contamination, ${ }^{[2]}$ which is dangerous to patients with weakened immune systems. ${ }^{[3]}$ High morbidity is observed for infections associated with urinary and venous catheters, stents, orthopedic and prosthetic implants, etc. $^{[4]}$ Each year, nearly 80000 cases of catheter-related bloodstream infections are reported from the use of more than 15 million central venous catheters in intensive care units across the United States. ${ }^{[5]}$ Various urinary catheters are extensively implanted in patients and they are the most important factor that triggers the urinary tract infections. ${ }^{[6]}$

The adhesion of microorganisms and subsequent biofilm formation on the surface of biomaterials are considered the major causes of biomedical device-associated infections. . $^{[7]}$ Biofilm is a complex community of surface-associated microorganisms encapsulated in a protective exopolysaccharide matrix. Compared to planktonic microbes, biofilms show up to 1000 times higher resistance to antimicrobial reagents. ${ }^{[8]}$ The higher dosage requirement of antibiotics in the treatment of biofilm-induced infections may result in a decline in their efficiency and the development of drug resistance. In recent years, the incidence of infections related to drug-resistant microbial strains has witnessed a significant increase. ${ }^{[9]}$ For instance, $53.9 \%$ of cases of Staphylococcus aureus infections tested
Y. Su, Q. Gao, M. Xie, M. Yu, Prof. B. Lei, Prof. P. Li

Center for Biomedical Engineering

and Regenerative Medicine

Frontier Institute of Science and Technology

Xi'an Jiaotong University

Xi'an 710054, China

E-mail: iampli@njtech.edu.cn

Z. Zhi, Prof. P. Li

Key Laboratory of Flexible Electronics (KLOFE)

and Institute of Advanced Materials (IAM)

Jiangsu National Synergetic Innovation Center

for Advanced Materials (SICAM)

Nanjing Tech University (NanjingTech)

Nanjing 211816, China

DOI: 10.1002/adhm.201601173
Prof. P. X. Ma

Department of Biomedical Engineering

University of Michigan

Ann Arbor, MI 48109, USA

Prof. P. X. Ma

Department of Biologic and Materials Sciences

University of Michigan

Ann Arbor, MI 48109, USA

Prof. P. X. Ma

Macromolecular Science and Engineering Center

University of Michigan

Ann Arbor, MI 48109, USA

Prof. P. X. Ma

Department of Materials Science and Engineering

University of Michigan

Ann Arbor, MI 48109, USA 
positive for methicillin-resistant $S$. aureus in a survey of hospitals in five cities of China (Shanghai 79.5\%, Beijing 56.4\%, Shenyang 50.0\%, Zhejiang 35.0\%, and Wuhan 31.6\%). ${ }^{[10]}$ New technologies are urgently required to combat infections caused by the implantation of biomedical devices without eliciting drug resistance.

In recent years, researchers are enthusiastic about antimicrobial coatings, especially new technologies that avoid the use of conventional antibiotics and do not alter the characteristics of material via the surface chemistry method. ${ }^{[11]}$ Antimicrobial coating on the surface of biomedical devices or implants may prevent the adhesion of microorganisms, inhibit their proliferation, or kill them. ${ }^{[12]}$ Lately, many researchers have put prodigious attention on coatings fabricated using antimicrobial polymers owing to their chemical versatility and robustness. ${ }^{[13]}$ Hydrophilic cationic polymer brush coatings exhibit potent antimicrobial activity and cell-adhesion resistance. ${ }^{[14-17]}$ However, the fabrication of these coatings normally involves multiple steps, ${ }^{[14]}$ high costs of the active materials, ${ }^{[15]}$ or rigorous water/ oxygen-free reaction conditions, ${ }^{[16]}$ etc. Photoinitiated surface grafting polymerization is a facile surface modification tool, ${ }^{[18]}$ we have developed several antimicrobial coatings using this method. ${ }^{[1,20]}$ Nonetheless, photoinduced grafting is not suitable for biomedical devices with complex shapes, such as those with internal lumen, etc. For vascular and urinary catheters, photografting cannot be used to achieve uniform coating on the surfaces of both the outer and inner lumen, whereas thermalinitiated reactions can be used to overcome this demerit.

In this study, we utilized thermal-initiated grafting to form a dual-functional antimicrobial and antifouling surface coating on silicone rubber (polydimethylsiloxane or PDMS, a commonly used catheter material). Autoclaving is a common and standard sterilization procedure for biomedical products, which can achieve a maximum temperature of $121^{\circ} \mathrm{C}$ for $15-20 \mathrm{~min}$. Under autoclaving conditions, surface attached initiators (e.g., peroxide/hydroperoxide groups generated via plasma activation) decompose and initiate grafting polymerization to form a permanent covalently bonded coating. Polyhexamethylene guanidine (PHMG) is a potent broad-spectrum antimicrobial that is thermally stable up to a temperature of $390{ }^{\circ} \mathrm{C}$ (both in air and argon atmosphere), which makes it a suitable candidate for thermal-initiating reactions. ${ }^{[21]}$ PHMG is also commercially available at a low cost and has been widely used in water treatment, wound care, and various other consumer applications. ${ }^{[22]}$ Its toxicity to humans is low, and its microbicidal effects are due to its ability to disrupt the microbial cell membrane, which is less likely to trigger drug resistance. ${ }^{[23]}$ Current applications of PHMG mainly utilize its solution form, but owing to its excellent stability, its accumulation in the environment poses a potential ecological issue. ${ }^{[24]}$ Covalent tethering of PHMG to the material surface prevents its contamination into the ecosystem.

One obvious disadvantage of cationic polymer-based surface coatings is the easy fouling by cell debris and biomolecules, leading to the loss of their antimicrobial activity and even promoting biofilm formation. ${ }^{[25]}$ Therefore, only antimicrobial activity is not sufficient to prevent biomaterial-associated infections; antifouling functionality is also required for an effective coating. ${ }^{[26]}$ Herein, block copolymers with multifunctional segments were rationally designed and synthesized via conjugation of the broad-spectrum antimicrobial, PHMG, with antifouling poly(ethylene glycol) (PEG), and the introduction of surface-tethering groups. PEG is a biocompatible hydrophilic polymer, which is capable of resisting protein/cell adhesion. ${ }^{[27]}$ Allyl-terminated PEG (APEG) was further functionalized with tosyl groups to obtain hetero-bifunctional APEG-OTs, which was then conjugated with PHMG to obtain APEG-PHMG block copolymers (Scheme 1A). PEGs with different molecular weights (1200 and $2400 \mathrm{Da}$ ) were used to investigate the influence on its biological properties. PHMG was also modified with allyl glycidyl ether (AGE) to obtain an allyl terminated PHMG (A-PHMG), which does not contain PEG segments. Both A-PHMG and APEG $_{1200 / 2400}$-PHMG were grafted on silicone rubber via a plasma/autoclave-assisted process, forming covalently grafted bottlebrush-like surface coatings (Scheme 1B). The antimicrobial activity of modified PHMG oligomers was investigated both in solution and coating form against typical gram-negative bacterium (Pseudomonas aeruginosa, American type culture collection (ATCC) 27853), gram-positive bacterium (Staphylococcus aureus, ATCC 2921), and fungus (Fusarium solani, ATCC 36031). The in vitro protein and platelet resistance, long-term reusability, antibiofilm efficacy, hemocompatibility, and cytotoxicity of A-PHMG and APEG $1200 / 2400^{-}$ PHMG coatings were also investigated. The in vivo infection resistant property of $\mathrm{APEG}_{2400}$-PHMG coating which showed the most potent in vitro antimicrobial and antifouling activities was explored in a rodent subcutaneous infection model.

\section{Results}

\subsection{Synthesis and Characterization of A-PHMG and APEG-PHMG Oligomers}

In this study, allyl terminated PHMG was synthesized by conjugation with AGE or APEG-OTs (Scheme 1A). The epoxy group of AGE is active for reaction with a variety of groups, such as amino, carboxyl, and hydroxyl groups, via the $\mathrm{S}_{\mathrm{N}} 2$ nucleophilic ring-opening substitution reaction. ${ }^{[28]}$ Hence, carbon-to-carbon double bond bearing PHMG was synthesized by the reaction of its terminal amino group with AGE, wherein the lone electron pair of the nitrogen atom attacks the positively charged carbon atom of the epoxy group, resulting in subsequent transfer of the proton. ${ }^{[29]}$ Moreover, in order to introduce PEG antifouling segment, hetero-bifunctional APEG-OTs was first synthesized. The end hydroxyl group of APEG was reacted with 4-toluene sulfonyl chloride ( $\mathrm{TsCl}$ ) to produce APEG-OTs. To investigate the effect of PEG chain length on its biological properties, APEGs with two different molecular weights (1200 and $2400 \mathrm{Da})$ were employed here. Thereafter, APEG-OTs were subjected to reaction with the amino group of PHMG to obtain the APEGPHMG diblock copolymer. The ${ }^{1} \mathrm{H}-\mathrm{NMR}$ spectra of A-PHMG, APEG-OTs, and APEG-PHMG oligomers, which reveal detailed structural information, are shown in Figure S1 (Supporting Information). New chemical shifts appear at $\delta=5.27$ (d), $5.29(\mathrm{~d}), 5.33\left(\mathrm{~d}^{\prime}\right), 5.37\left(\mathrm{~d}^{\prime}\right)$ in the spectrum of A-PHMG, and at $\delta=5.17(\mathrm{f}), 5.19(\mathrm{f}), 5.25\left(\mathrm{f}^{\prime}\right), 5.27\left(\mathrm{f}^{\prime}\right)$ in the spectrum of APEG-PHMG, which represent the peaks of terminal $\mathrm{C}-\mathrm{H}$ bonds in the allyl group. Variations in the ${ }^{1} \mathrm{H}$-NMR spectra of 
A

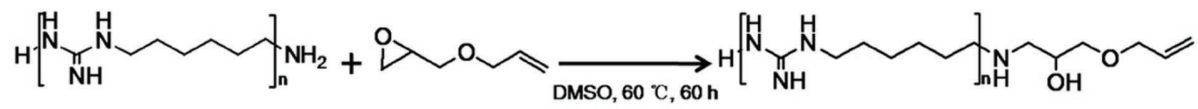

PHMG

AGE

A-PHMG<smiles>C=CCOCCCO</smiles>

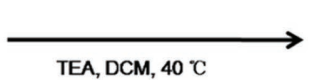

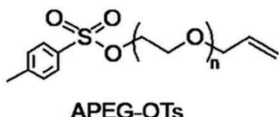<smiles>C=CCOCCN(C)CCCCCCCNC(C)NCNCN</smiles>

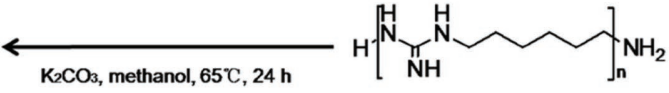

APEG-PHMG

PHMG

\section{B}

Plasma Activation

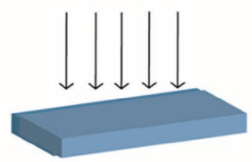

Polymer Substrate
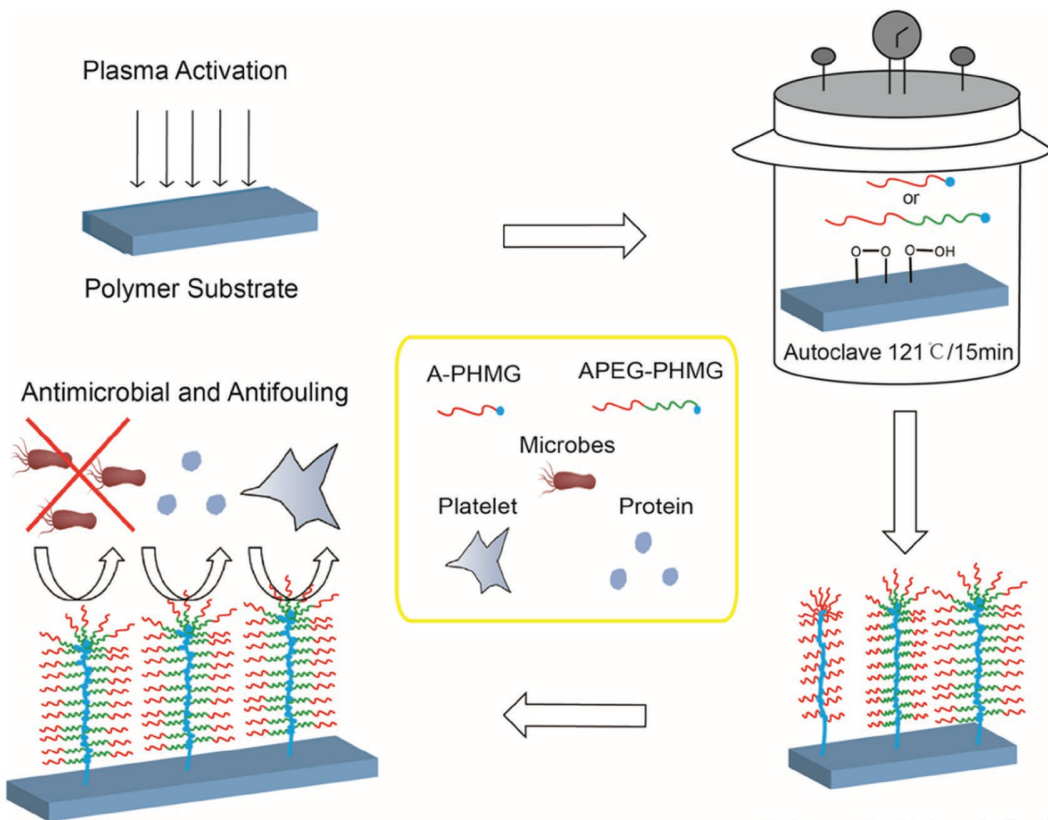

Polymer Bottlebrush Surface

Scheme 1. A) Synthesis of A-PHMG and APEG-PHMG oligomers. B) Schematic of plasma/autoclave-assisted grafting of A-PHMG/APEG-PHMG bottlebrushes on polymeric substrates.

the products validate the successful chemical reaction between AGE as well as APEG-OTs and the PHMG oligomer.

\subsection{Minimum Inhibitory Concentration of Modified PHMG Oligomers}

The antimicrobial activity of AGE and APEG modified PHMG oligomers in solution form was determined using a broth microdilution minimum inhibitory concentration (MIC) assay. Pristine PHMG exhibits excellent broad-spectrum antimicrobial activity against gram-negative $P$. aeruginosa, gram-positive $S$. aureus, and fungus F. solani, with low MIC in the range of 2.5-5.0 $\mu \mathrm{g} \mathrm{mL}^{-1}$ (Table 1). After coupling with AGE, the MIC of A-PHMG against the three tested microbes did not change. Coupling with APEG-OTs resulted in a marginal increase of MIC for APEG-PHMG block copolymers against the three microbes. The MIC of $\mathrm{APEG}_{1200}$-PHMG against $S$. aureus and F. solani increased twofold to $5.0 \mu \mathrm{g} \mathrm{mL} \mathrm{m}^{-1}$, whereas it did not change against $P$. aeruginosa. MIC further increased with PEG chain length. The MIC of $\mathrm{APEG}_{2400}$-PHMG against the three tested microbes is $10.0 \mu \mathrm{g} \mathrm{mL} \mathrm{m}^{-1}$, which is twofold higher

Table 1. Minimum inhibitory concentration (MIC) of modified PHMC oligomers.

\begin{tabular}{|c|c|c|c|}
\hline \multirow[t]{2}{*}{$\mathrm{MIC}\left[\mu \mathrm{g} \mathrm{mL}^{-1}\right]$} & Gram-negative $(\mathrm{G}-)$ & Gram positive $(\mathrm{G}+)$ & Fungus \\
\hline & P. aeruginosa & S. aureus & F. solani \\
\hline PHMG & 5.0 & 2.5 & 2.5 \\
\hline A-PHMG & 5.0 & 2.5 & 2.5 \\
\hline $\mathrm{APEG}_{1200}-\mathrm{PHMG}$ & 5.0 & 5.0 & 5.0 \\
\hline $\mathrm{APEG}_{2400}-\mathrm{PHMG}$ & 10.0 & 10.0 & 10.0 \\
\hline
\end{tabular}


than those of $\mathrm{APEG}_{1200}$-PHMG against the same microbes. Although the MIC increased twofold to fourfold after coupling with APEG, $10.0 \mu \mathrm{g} \mathrm{mL}^{-1}$ is still a sufficiently low concentration for the effective inhibition of microbes.

\subsection{Surface Characterizations of PHMG-Based Coatings}

Allyl-terminated A-PHMG and APEG-PHMG oligomers were initiated through a plasma/autoclave-assisted surface grafting reaction, forming bottlebrush-like coatings on the surface of PDMS silicone rubber. The process is illustrated in Scheme 1B. First, the surface of PDMS was treated with argon plasma $(13.56 \mathrm{MHz})$ treatment at $40 \mathrm{~W}$ and $25 \mathrm{sccm}$ for $5 \mathrm{~min}$ to generate reactive free radicals. Argon plasma-treated PDMS was then placed in air for another $15 \mathrm{~min}$, where oxygen and water in the air could react with nascent radicals to produce relatively stable peroxide or hydroperoxide groups. ${ }^{[30]}$ Then, the activated surfaces were immersed in vials containing $5 \mathrm{wt} \%$ of A-PHMG or APEG-PHMG oligomer solution and autoclaved at $121{ }^{\circ} \mathrm{C}$ for $15 \mathrm{~min}$. Peroxide/hydroperoxide groups on the silicone surface decompose under high temperatures and generate free radicals that initiate the polymerization of allyl groups. Thus, A-PHMG/APEG-PHMG oligomers were covalently grafted on plasma-activated silicone surfaces by autoclaving, which generated a dense bottlebrush-like coating.

Contact angles were measured to evaluate the surface hydrophilicity of modified PHMG-coated PDMS slides. As shown in Figure S2 (Supporting Information), PDMS is inherently hydrophobic with a high contact angle of $104.4^{\circ} \pm 2.6^{\circ}$. Grafting of A-PHMG on PDMS significantly decreased its hydrophobicity, indicated by a greatly reduced contact angle of $41.5^{\circ} \pm 2.8^{\circ}$. The introduction of PEG segments into the polymer bottlebrushes further increased the hydrophilicity of the surface, with contact angles of $37.5^{\circ} \pm 2.2^{\circ}$ and $29.5^{\circ} \pm 3.5^{\circ}$ for $\mathrm{APEG}_{1200}-\mathrm{PHMG}$ and $\mathrm{APEG}_{2400}-\mathrm{PHMG}$ coatings, respectively.

PHMG-based coatings on the surface of PDMS were further characterized with X-ray photoelectron spectroscopy (XPS). The XPS wide scan spectra shown in Figure 1A demonstrate the presence of $\mathrm{C} 1 \mathrm{~s}, \mathrm{O} 1 \mathrm{~s}, \mathrm{~N} 1 \mathrm{~s}, \mathrm{Si} 2 \mathrm{~s}$, and Si2p peaks in pristine PDMS, PDMS-g-A-PHMG, and PDMS-g-APEG $2400^{-}$ PHMG coatings. In the high-resolution scan spectra shown in Figure 1B, the N1s peak at $399.7 \mathrm{eV}$, which represents the nitrogen atom in the guanidine group, is negligible in pristine PDMS but significantly increased in PDMS-g-A-PHMG and PDMS-g-APEG ${ }_{2400}-$ PHMG coatings. The increased amplitude of this peak indicates successful coating of PHMG on the surface of PDMS. In the high-resolution C1s spectra of PDMS-g-APHMG and PDMS-g-APEG 2400 -PHMG, shown in Figure 1C,D,
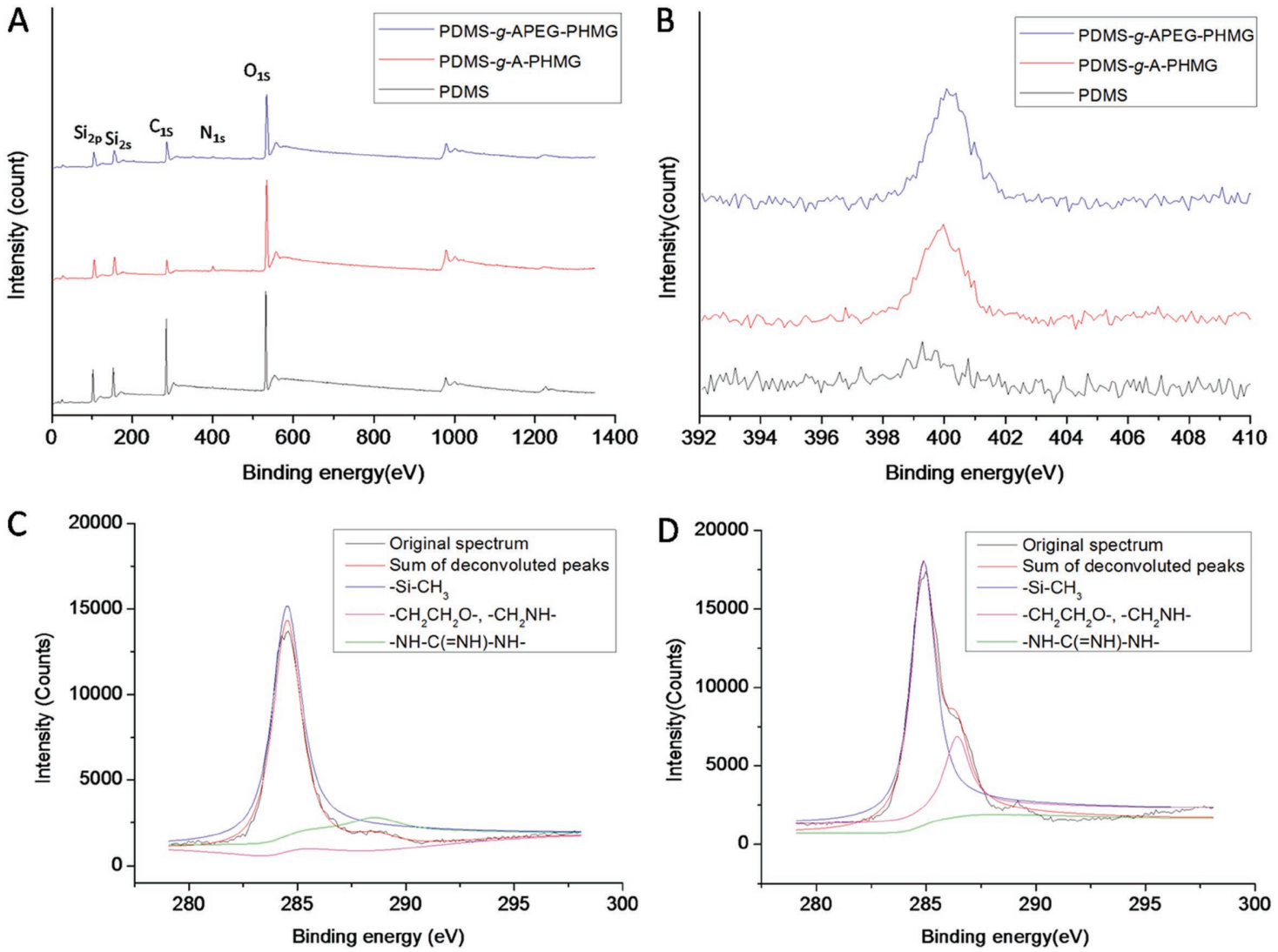

Figure 1. A) XPS survey spectra and B) high-resolution N1s spectra of pristine PDMS, PDMS-g-A-PHMG, and PDMS-g-APEG 2400 -PHMG. High-resolution Cls spectra of C) PDMS-g-A-PHMG and D) PDMS -g-APEG $2400^{-}$PHMG. 

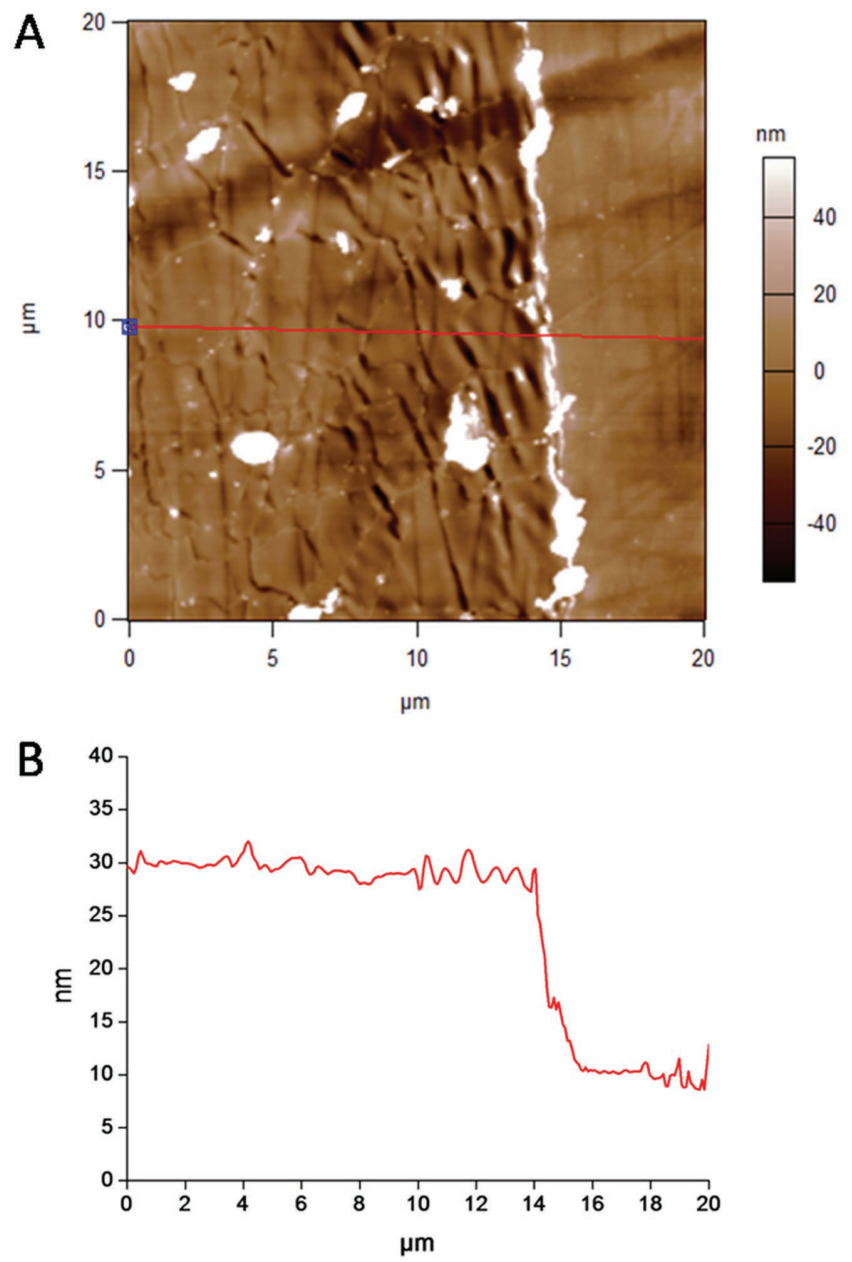

Figure 2. A) Surface morphology of pristine PDMS (right side) and APEG $_{2400}$-PHMG coating (left side) scanned by AFM. B) Coating thickness was measured to be $20 \pm 5 \mathrm{~nm}$.

respectively, the increase of the $-\mathrm{CH}_{2}-\mathrm{CH}_{2}-\mathrm{O}-$ signal clearly demonstrates the existence of PEG segments in the PDMS-g$\mathrm{APEG}_{2400}$-PHMG coating. These results confirm the successful grafting of A-PHMG and APEG-PHMG on PDMS.

The surface morphology and thickness of the $\mathrm{APEG}_{2400^{-}}$ PHMG coating were characterized with atomic force microscopy (AFM). An AFM image at the border of $\mathrm{APEG}_{2400}$-PHMG coating and pristine PDMS surface is shown in Figure 2A. Pristine PDMS has a smooth morphology, whereas the $\mathrm{APEG}_{2400^{-}}$ PHMG coating has a rough, "crinkled" morphology. The determined thickness of the coating is $20 \pm 5 \mathrm{~nm}$. These results clearly indicate the successful grafting of uniform $\mathrm{APEG}_{2400^{-}}$ PHMG coating on the surface of PDMS.

\subsection{In Vitro Antimicrobial Activity of PHMG-Based Coatings}

After confirmation of the successful grafting of A-PHMG and APEG-PHMG on the silicone surface, the antimicrobial properties of A-PHMG and APEG-PHMG coatings were investigated against three typical pathogenic microbes (gram-negative $P$. aeruginosa, gram-positive $S$. aureus, and fungus $F$. solani) by using a contact protocol. In this assay, $10 \mu \mathrm{L}$ of $1 \times 10^{8}$ colony forming unit (CFU) $\mathrm{mL}^{-1}$ microbial inoculum was spread onto the surface of A-PHMG/APEG $1200 / 2400-\mathrm{PHMG}$-coated PDMS slides and incubated at $37{ }^{\circ} \mathrm{C}$ (bacteria) or $28{ }^{\circ} \mathrm{C}$ (fungi) for $1 \mathrm{~h}$, followed by CFU determination. Uncoated PDMS slides were used as the control group. The results indicate that both modified-PHMG oligomer coatings are highly antimicrobial. No visible colonies were observed on coated PDMS slides after $1 \mathrm{~h}$ contact (shown in Table 2). Both the A-PHMG and $\mathrm{APEG}_{1200 / 2400}$-PHMG coatings inhibited more than $99.9 \%$ of all three tested microbes. These results demonstrate that the potent broad-spectrum antimicrobial activity of A-PHMG and APEG $_{1200 / 2400}$-PHMG oligomers was retained after thermalinduced surface immobilization by autoclaving.

\subsection{Protein Fouling Assay}

The antifouling property of PHMG-based coatings was first investigated using a protein adsorption assay. Three proteins (bovine serum albumin (BSA), lysozyme, and fibrinogen) were used to investigate the protein-resistance of A-PHMG and APEG $_{1200 / 2400}$-PHMG coatings, and the amount of adsorbed protein was quantified using the bicinchoninic acid (BCA) method (calibration curves of the three proteins are shown in Figure S3 in the Supporting Information). As shown in Figure 3, pristine PDMS silicone rubber surface adsorbed relatively high amounts of BSA $\left(0.91 \mu \mathrm{g} \mathrm{cm} \mathrm{cm}^{-2}\right)$, lysozyme $\left(0.97 \mu \mathrm{g} \mathrm{cm}^{-2}\right)$, and fibrinogen $\left(1.33 \mu \mathrm{g} \mathrm{cm} \mathrm{cm}^{-2}\right)$. Grafting of A-PHMG on the PDMS surface reduced the adsorption of BSA $\left(0.21 \mu \mathrm{g} \mathrm{cm}{ }^{-2}\right)$, lysozyme $\left(0.13 \mu \mathrm{g} \mathrm{cm} \mathrm{cm}^{-2}\right)$, and fibrinogen $\left(0.15 \mu \mathrm{g} \mathrm{cm} \mathrm{cm}^{-2}\right)$. The presence of PEG segments in $\mathrm{APEG}_{1200 / 2400}$-PHMG coatings further reduced protein adsorption. The $\mathrm{APEG}_{1200}$-PHMG-coated PDMS surface adsorbed lower amounts of BSA $\left(0.17 \mu \mathrm{g} \mathrm{cm}^{-2}\right)$, lysozyme $\left(0.08 \mu \mathrm{g} \mathrm{cm}^{-2}\right)$, and fibrinogen $\left(0.13 \mu \mathrm{g} \mathrm{cm}^{-2}\right)$. With the increasing of PEG length, the protein adsorption amounts on $\mathrm{APEG}_{2400}-\mathrm{PHMG}$ coated surfaces were continually decreased to even lower of BSA $\left.(0.11 \mu \mathrm{g} \mathrm{cm})^{-2}\right)$, lysozyme $\left(0.05 \mu \mathrm{g} \mathrm{cm}^{-2}\right)$, and fibrinogen $\left(0.09 \mu \mathrm{g} \mathrm{cm}^{-2}\right)$. Thus, the $\mathrm{APEG}_{2400}$-PHMG coating showed the lowest protein adsorption of BSA, lysozyme, and fibrinogen, which was reduced by $88 \%, 95 \%$, and $93 \%$, respectively, compared to that on pristine PDMS. Protein adsorption was also

Table 2. Kill ratio (\%) of PHMG-based coatings against three microbes.

\begin{tabular}{|c|c|c|c|c|c|c|}
\hline \multirow[t]{2}{*}{ Coatings } & \multicolumn{2}{|c|}{ P. aeruginosa } & \multicolumn{2}{|c|}{ S. aureus } & \multicolumn{2}{|c|}{ F. solani } \\
\hline & CFU & Kill ratio [\%] & CFU & Kill ratio [\%] & CFU & Kill ratio [\%] \\
\hline PDMS-g-A-PHMG & 0 & $>99.9$ & 0 & $>99.9$ & 0 & $>99.9$ \\
\hline PDMS-g-APEG 1200 -PHMG & 0 & $>99.9$ & 0 & $>99.9$ & 0 & $>99.9$ \\
\hline PDMS-g-APEG $2400^{-P H M G}$ & 0 & $>99.9$ & 0 & $>99.9$ & 0 & $>99.9$ \\
\hline
\end{tabular}



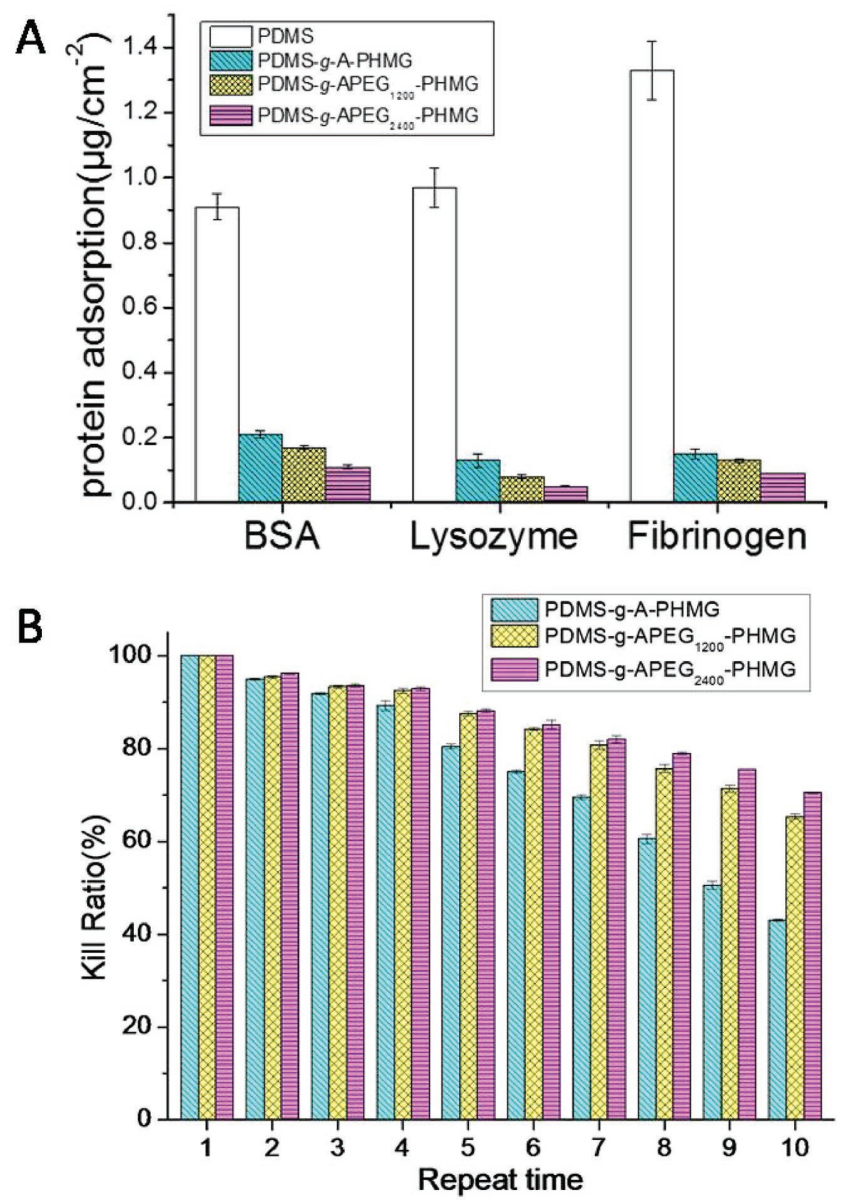

Figure 3. A) Protein adsorption property of pristine and A-PHMG/APEGPHMG coated PDMS surfaces. B) Long-term reusable antimicrobial activity of A-PHMG and APEG-PHMG coatings by repeat challenge with $10^{8} \mathrm{CFU} \mathrm{mL} \mathrm{m}^{-1}$ of $P$. aeruginosa up to ten cycles.

visualized using fluorescein isothiocyanate-labeled BSA (BSAFITC). As shown in Figure S4 (Supporting Information), similar tendency was obtained with aforesaid results. Extensive fluorescence of adsorbed BSA-FITC was observed on pristine PDMS, which was reduced on A-PHMG and APEG $1200 / 2400^{-}$ PHMG coatings. The observed reduction in protein adsorption on A-PHMG and APEG $1200 / 2400$-PHMG coatings is attributed to increased hydrophilicity and the presence of antifouling PEG segments.

\subsection{In Vitro Reusable Antimicrobial Property of PHMB-Based Surface Coatings}

One of the key drawbacks of cationic antimicrobial coatings is their easy fouling by anionic debris, such as that of dead cells, which masks the coating and greatly reduces their active lifetime. In this study, A-PHMG and APEG $1200 / 2400^{-}$PHMG coatings were repeatedly challenged with $P$. aeruginosa for ten times to investigate the long-term antimicrobial activity of the coatings. As shown in Figure 3B, all three coatings achieved a inhibition ratio of more than $90 \%$ during the initial three challenge rounds. At the fourth challenge round, the kill ratio percent of PDMS-g-A-PHMG dropped to $89.23 \% \pm 1.02 \%$, whereas that of PDMS-g-APEG $1200 / 2400$-PHMG was $92.45 \% \pm$ $0.58 \%$ and $92.89 \% \pm 0.45 \%$, respectively. After the fourth challenge round, the antimicrobial potency of PDMS-g-A-PHMG decreased rapidly to $42.98 \% \pm 0.18 \%$ kill ratio at challenge round ten. In contrast, the antimicrobial potency of PDMSg-APEG $1200 / 2400$-PHMG was consistently higher than that of A-PHMG coating, which lacked PEG antifouling segments. A longer PEG chain led to higher antimicrobial potency. The kill ratio percent of PDMS-g-APEG 2400 -PHMG was marginally higher than that of PDMS-g-APEG 1200 -PHMG between rounds two and ten. At the tenth challenge round, PDMS-g-APEG $2400^{-}$ PHMG still exhibited a $70.48 \% \pm 0.27 \%$ kill ratio against $10^{8} \mathrm{CFU} \mathrm{mL} \mathrm{m}^{-1}$ of $P$. aeruginosa. Thus, among the coatings tested, $\mathrm{APEG}_{2400}$-PHMG coating exhibited the most potent long-term antimicrobial efficacy.

\subsection{Antibiofilm Properties}

Once the bacteria successfully adhered to the surface, it will manage to proliferate rapidly to form biofilm. Thus, antibiofilm activity is imperative for the prevention of biomaterialassociated infections. The antibiofilm activity of PHMG-based coatings against $P$. aeruginosa was investigated here. As shown in Figure 4, numerous $P$. aeruginosa cells adhered to the pristine PDMS surface after $5 \mathrm{~d}$ culture. Corresponding LIVE/DEAD staining indicated that the majority of cells were alive, suggesting biofilm growth on the pristine PDMS surface. In contrast, the number of adherent bacteria greatly reduced on A-PHMG-coated PDMS slides, and only a few bacteria were observed on the surface (Figure 4C,D). The presence of PEG segments in $\mathrm{APEG}_{1200 / 2400}$-PHMG coatings further reduced the number of adherent bacteria (Figure 4E$\mathrm{H})$. Nominal number of bacteria adhered on the surface of $\mathrm{APEG}_{2400}$-PHMG coating. These results are consistent with the protein-resistant and reusable antimicrobial properties of the coatings.

\subsection{Platelet Adhesion and Hemolytic Properties}

Devices/implants that contact blood may trigger platelet adhesion, coagulation, and thrombus formation. Therefore, hemocompatibility is a critical factor for effective coatings. Platelet adhesion on pristine and A-PHMG/APEG $1200 / 2400$-PHMG coated PDMS surfaces was studied by contact with rabbit platelet-rich plasma, and observed by field emission scanning electronic microscope (FESEM). The results shown in Figure $\mathbf{5}$ demonstrate differences in the platelet adhesion properties of pristine PDMS and three PHMG-based coating surfaces. As shown in Figure 5A, a large number of platelets adhered on the surface of pristine PDMS. The grafting of A-PHMG significantly reduced the amount of platelet adhesion, presumably owing to its improved hydrophilicity (Figure 5B). The introduction of antifouling PEG segments further reduced platelet adhesion on APEG $_{1200 / 2400}$-PHMG coatings; nearly no platelets were observed on the surface, as shown in in Figure 5C,D. 

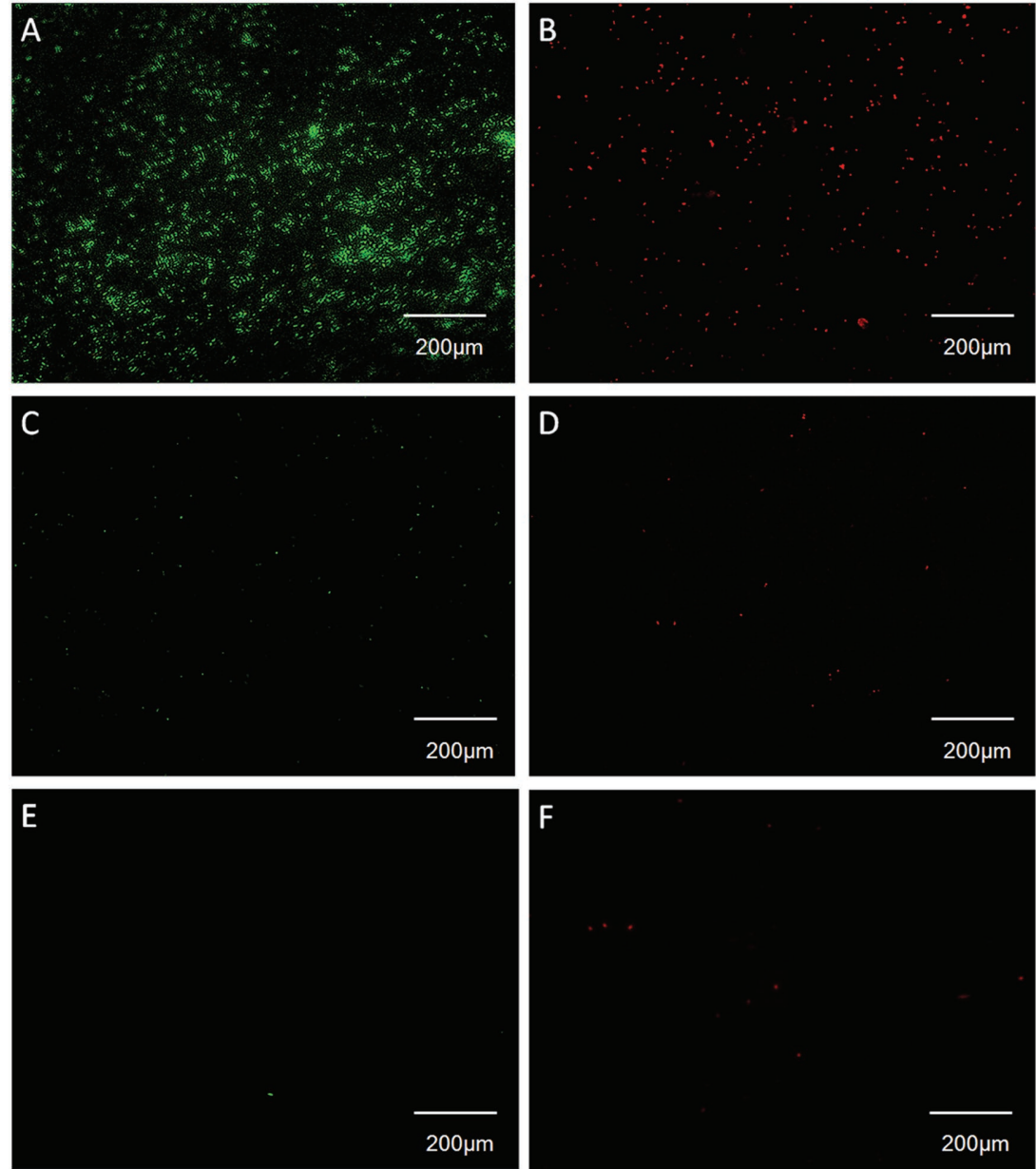

$\mathrm{F}$
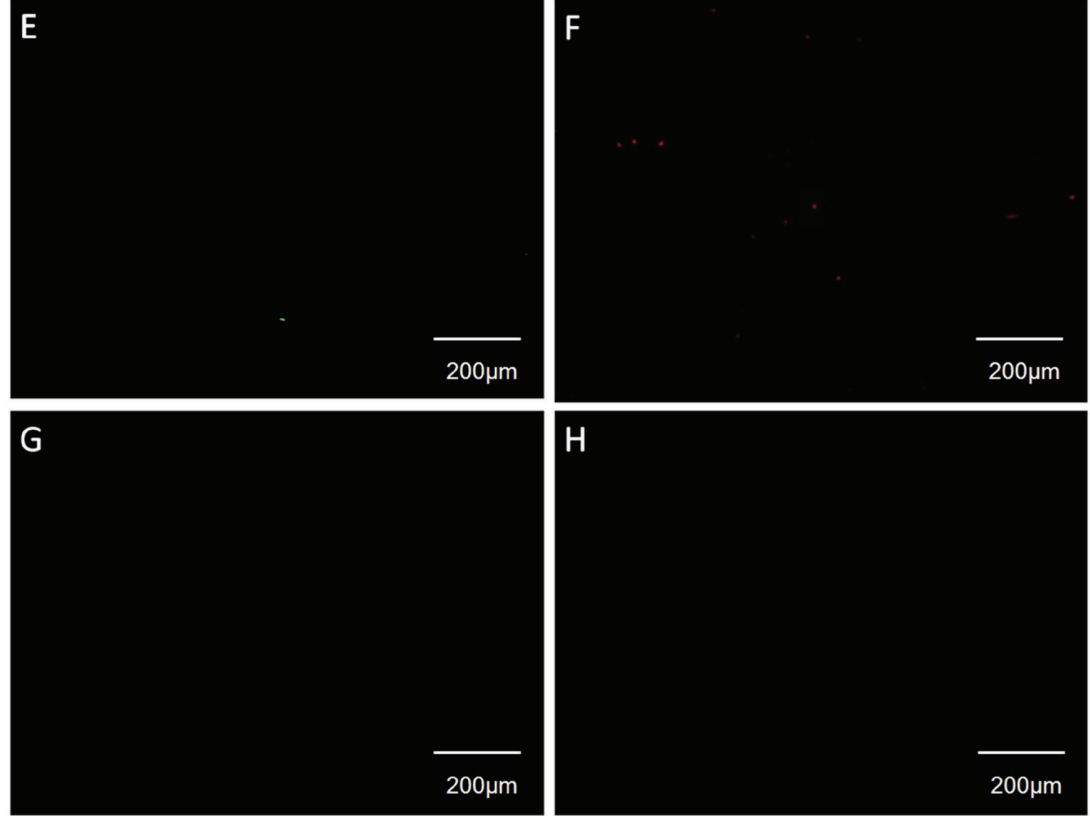

Figure 4. $P$. aeruginosa biofilm formation after $5 \mathrm{~d}$ of growth on the surfaces of $A, B$ ) pristine

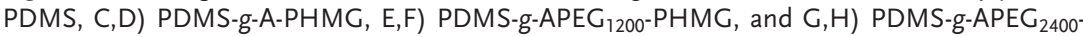
PHMG. Biofilms were LIVE/DEAD stained and imaged with an inverted fluorescence microscope (left column is LIVE and right column is DEAD).

Moreover, the number of surface-adhered platelets was also quantified from FESEM images, and the results are summarized in Figure 5E. There were $(1.56 \pm 0.21) \times 10^{5}$ cells cm $\mathrm{cm}^{-2}$ on pristine PDMS, and $(0.51 \pm 0.12) \times 10^{5}$ cells cm $^{-2}$ on A-PHMGcoated PDMS surfaces. The number of surface-adhered platelets further decreased to $(0.14 \pm 0.03) \times 10^{5}$ and $(0.03 \pm 0.02) \times$ $10^{5}$ cells $\mathrm{cm}^{-2}$ on $\mathrm{APEG}_{1200}$-PHMG- and $\mathrm{APEG}_{2400}$-PHMGcoated PDMS surfaces, respectively.

The hemolytic activity of A-PHMG and APEG $1200 / 2400^{-}$ PHMG coatings was also determined by contacting with rabbit red blood cells, pristine PDMS was used as the negative control group. After contact with a $5.0 \%(\mathrm{v} / \mathrm{v})$ erythrocyte suspension for $1 \mathrm{~h}$, hemolysis was less than $2 \%$ for all three coatings, which include A-PHMG and APEG $1200 / 2400$-PHMG, with no statistical differences from the control groups (Figure S5, Supporting Information). These results indicated that modified PHMG-based coatings are nontoxic to red blood cells. On the basis of the in vitro antimicrobial, protein adsorption, reusability, antibiofilm, and hemocompatible properties, PDMS-g-APEG 2400 -PHMG shows the most optimal antimicrobial and antifouling activities among the three coatings. Hence, the in vitro cytotoxicity and in vivo infection resistance of $\mathrm{APEG}_{2400}$-PHMG coating were further studied in the following experiments.

\subsection{In Vitro Cytotoxicity Studies}

The cytotoxicity of PDMS-g-APEG 2400 -PHMG was determined with human aorta smooth muscle cells (SMCs) using the 3-(4,5-dimethyl-2-thiazolyl)-2,5-diphenyl-2-H-tetrazolium bromide (MTT) and LIVE/DEAD cell viability assays. PDMS-g-APEG 2400 -PHMG and pristine PDMS slides were cultured with mammalian cells for up to $5 \mathrm{~d}$, tissue culture polystyrene (TCPS) plates were used as control group. At days 1, 3, and 5, the cell viability was determined using the MTT assay and also observed with LIVE/DEAD staining. As shown in Figure 6, mammalian cells continue to grow for up to $5 \mathrm{~d}$ when in contact with PDMS-g-APEG ${ }_{2400}$-PHMG and pristine PDMS surfaces. Based on the MTT assay, there is no significant difference $(p>$ 0.05 ) in the cell viability among cells cultured with PDMS-g-APEG 2400 -PHMG, pristine PDMS, and on TCPS (Figure 6A). As shown in Figure 6B, the LIVE/DEAD staining results indicate most of the mammalian cells growing well up to $5 \mathrm{~d}$ of incubation by contacting with the slides, which validated the results from the MTT assay. These results demonstrate that PDMS-g-APEG 2400 -PHMG slides do not display significant toxicity to mammalian cells.

\subsection{In Vivo Anti-Infection Evaluation}

The $\mathrm{APEG}_{2400}$-PHMG coating was further evaluated in an animal infection model. $P$. aeruginosa was used as the model microbe for a subcutaneous implant-associated infection. Silicone implants with and without $\mathrm{APEG}_{2400}$-PHMG coating were 

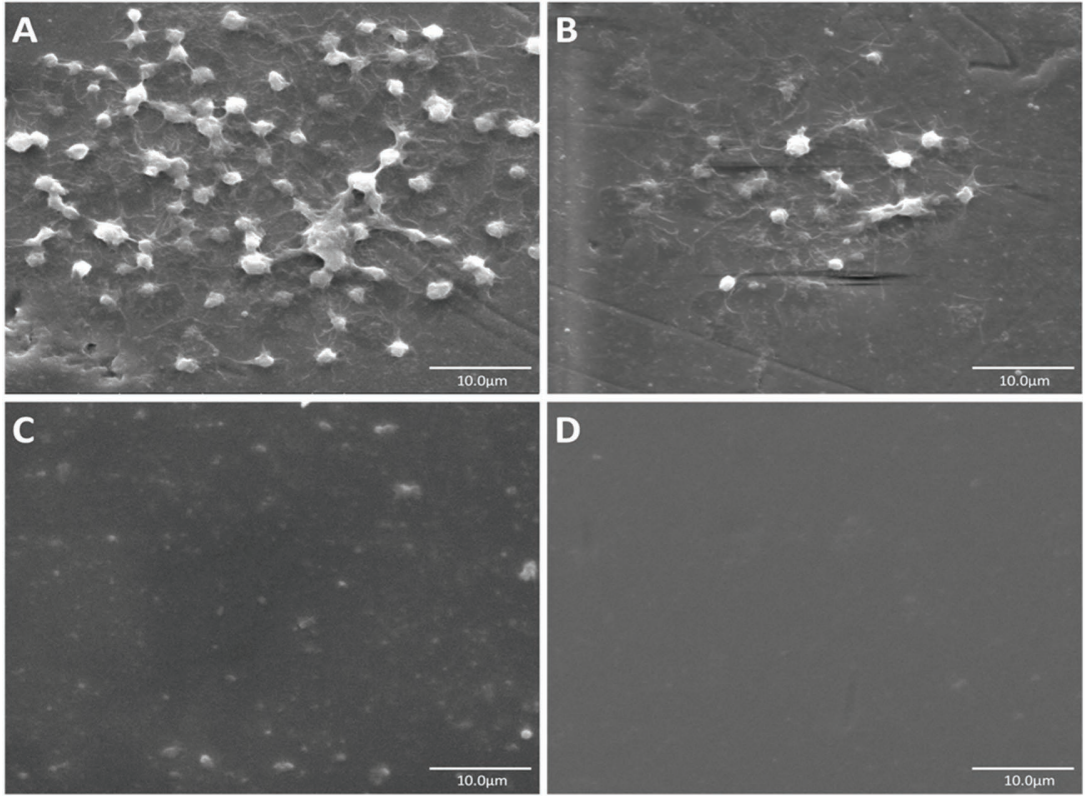

E

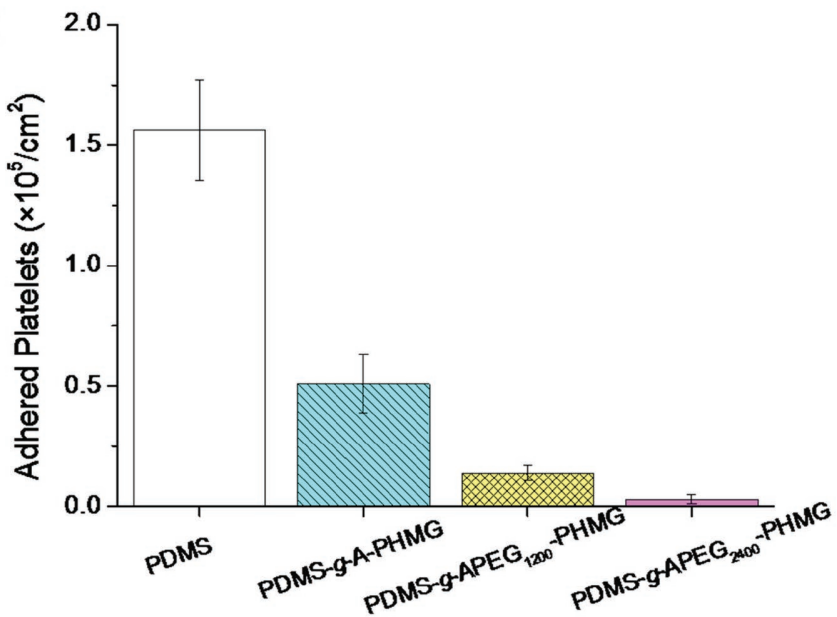

Figure 5. Blood platelet adhesion observed by FESEM, on A) pristine PDMS, amounts of adherent platelets were observed; B) PDMS-g-A-PHMG, less adherent platelets were observed; C) PDMS-g-APEG $1200^{-P H M G}$; and D) PDMS-g-APEG $2400^{-}$PHMG, little to no adherent platelets were observed. E) Quantification of the number of adherent platelets on each of the indicated surfaces.

preseeded with bacteria and then implanted in the back of rats. The surgical incision site after implantation and suturing of uncoated silicone (left side) and $\mathrm{APEG}_{2400}$-PHMG coated silicone (right side) is shown in Figure 7A. $5 \mathrm{~d}$ after the surgery, hallmarks of infection, including suppuration of pus, were visible at the wound site implanted with uncoated silicone (Figure 7B), whereas the same hallmarks of inflammation were not observed at the wound site implanted with $\mathrm{APEG}_{2400^{-}}$ PHMG coated silicone (Figure 7C). Implants were surgically removed and the surface-adhered bacteria were detached by sonication and quantified by agar plate colony counting. As shown in Figure 7D, all eight implants of uncoated silicone group exhibited high numbers of surface attached $P$. aeruginosa in the range from $1.86 \times 10^{5}$ to $3.72 \times 10^{6} \mathrm{CFU}$ per implant (5.27-6.57 $\log \mathrm{CFU}$ ), with an average number of $8.91 \times 10^{5} \mathrm{CFU}$ per implant (5.95 log CFU). In contrast, significantly less $P$. aeruginosa was detached from $\mathrm{APEG}_{2400}$-PHMG coated silicone implants. Four out of eight implants yielded no observable bacterial colonies, and the other four implants harbored bacterial numbers in the range of 3-16 CFU per implant (0.44-1.22 log CFU). The average number of bacteria detached from $\mathrm{APEG}_{2400}$-PHMG coated implants was 2.19 CFU per implant (0.34 log CFU). Thus, APEG 2400 -PHMG coating exhibits potent in vivo antimicrobial efficacy and effectively reduce $P$. aeruginosa growth/survival by 5.61 log reduction.

The tissues surrounding the uncoated and $A P E G_{2400}$-PHMG coated implants were sectioned and hematoxylin and eosin (H\&E)stained for histological study. As shown in Figure $8 \mathrm{~A}, \mathrm{~B}$, abundant numbers of stained inflammatory cells (blue color) were visible in the representative tissue that contacted the uncoated silicone implant, demonstrating infection at this site. In contrast, as shown in Figure 8C,D, fewer inflammatory cells are visible in the tissue surrounding $\mathrm{APEG}_{2400^{-}}$ PHMG coated silicone implants. Moreover, the number of inflammatory cells in both sections was counted and the results are shown in Figure 8E. There were $(5.47 \pm 0.79) \times 10^{4}$ inflammatory cells $\mathrm{cm}^{-2}$ in the three representative sections of the tissue surrounding uncoated silicone implants, whereas the number decreased by more than $90 \%$ to $(0.54 \pm 0.12) \times 10^{4}$ inflammatory cells cm${ }^{-2}$ in tissues surrounding $\mathrm{APEG}_{2400}$-PHMG coated implants.

These results demonstrate that $\mathrm{APEG}_{2400^{-}}$ PHMG coating successfully inhibits a biomedical implant-associated infection in vivo.

\section{Discussion}

Silicone is a widely used material for biomedical applications owing to its chemical and thermal stability, biodurability, and biocompatibility. ${ }^{[31]}$ However, its inherent hydrophobic nature can lead to complications when in contact with body fluids after implantation, the biomolecules and microbes can easily attach on the surface and potentially lead to biofilm formation. ${ }^{[32]}$ Therefore, modifying silicone surfaces to impart antifouling and antimicrobial properties has attracted considerable attention in recent years. ${ }^{[33-37]}$ Biocidal release strategy has been utilized, either by incorporating antimicrobials into the silicone bulk material or by adsorbing antimicrobials onto the surface of silicone. ${ }^{[3,34]}$ However, the blending of antimicrobial regents with silicone explicitly affects the inherent characteristics of silicone, such as its mechanical property and transparency. In addition, the lifetime of this "leaching" strategy is restricted by the limitation 
A

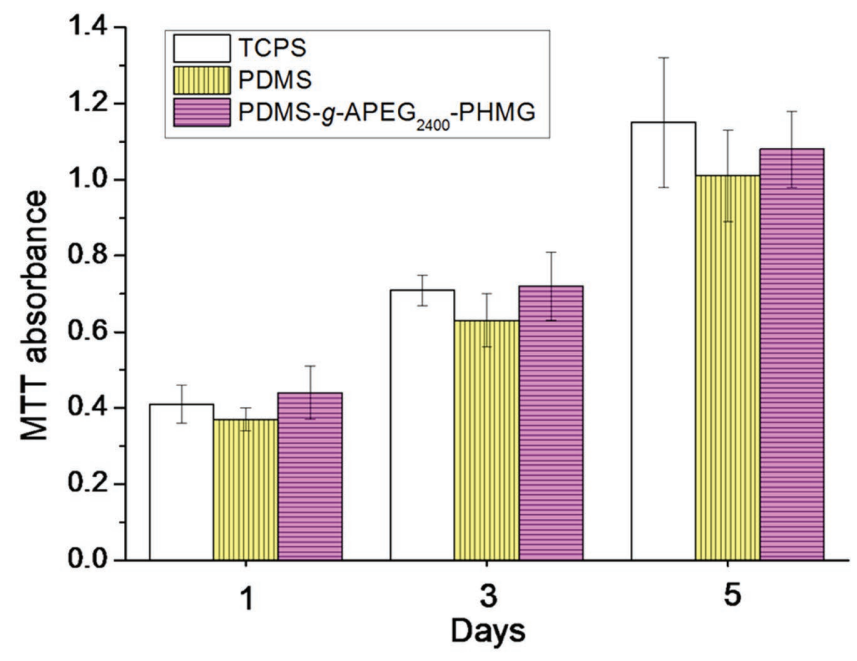

B

Day1

Day3

Day5
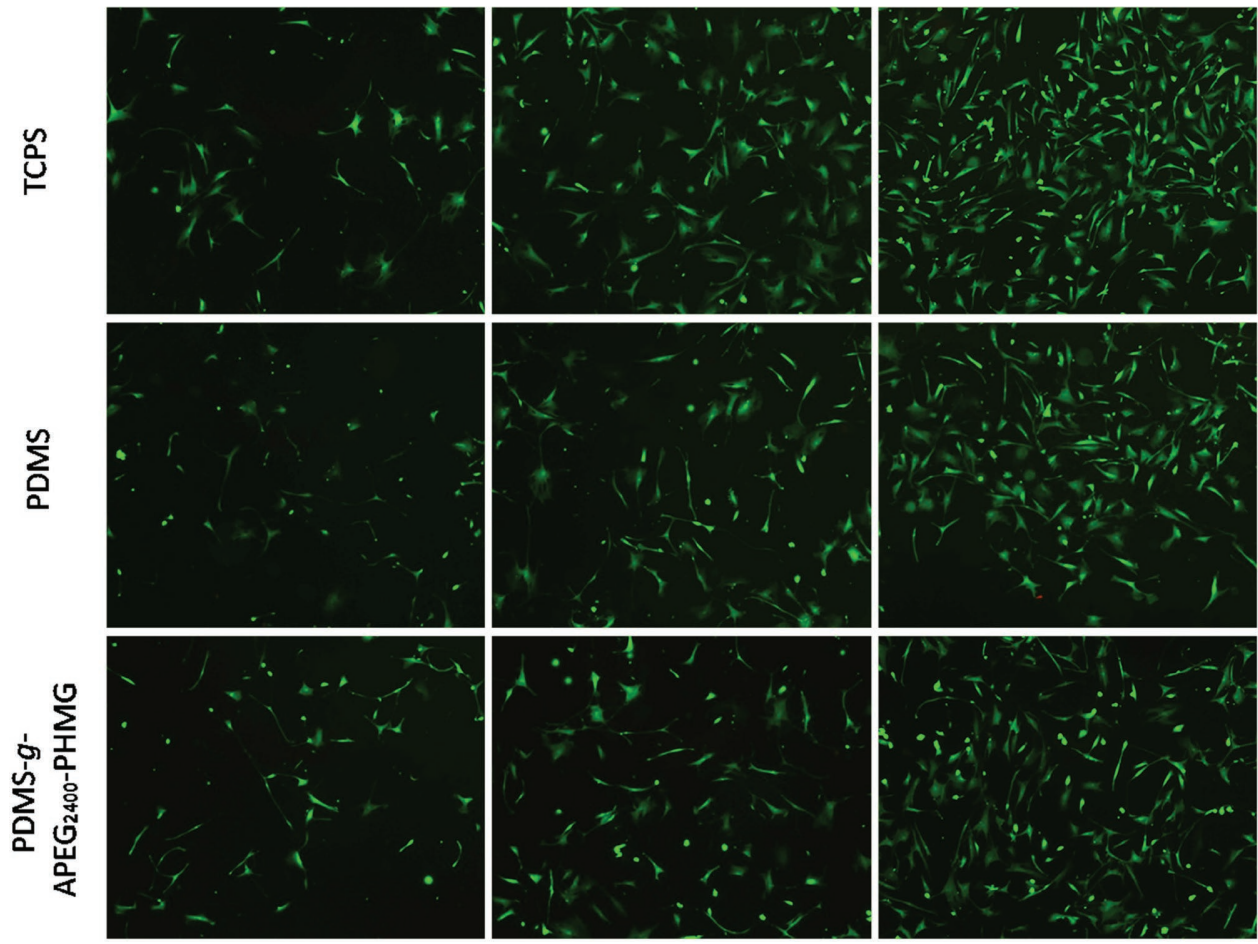

Figure 6. Cytotoxicity of PDMS-g-APEG 2400 -PHMG slides in contact with mammalian smooth muscle cells, as determined by A) MTT cell viability assay and B) LIVE/DEAD staining at 1, 3, and $5 \mathrm{~d}$. Cell growth was unaffected by incubation with PDMS-g-APEG $2400^{-}$PHMG and pristine PDMS slides for up to $5 \mathrm{~d}$. There is no significant difference $(p>0.05)$ in the viability of cells in contact with PDMS-g-APEG $2400^{-P H M G, ~ p r i s t i n e ~ P D M S, ~ a n d ~ c o n t r o l ~}$ TCPS groups.

of drug loading amount. ${ }^{[33]}$ Neutral hydrophilic polymer brush/ hydrogel coatings also have been developed to improve the antifouling activity of silicone materials. ${ }^{[35,36]}$ Antifouling strategy alone is capable of reducing the adhesion of microbes but are ineffective at killing or inhibiting microbes, and thus are only suitable for certain short-term applications. ${ }^{[26]}$ Contact-active antimicrobial coatings fabricated with cationic antimicrobial peptide or polymers are able to kill microbes that contact the surface. However, some of these coatings are challenged by one or more problems including hemolysis, cytotoxicity, protein and platelet adhesion, etc. ${ }^{25,38]}$ In view of this, dual-functional antimicrobial and antifouling coatings should be developed to overcome the aforementioned shortcomings through rational design. The ideal coating should possess high potent broadspectrum antimicrobial efficacy, excellent antifouling activity, such as protein and platelet resistance, low hemolysis, and biocompatibility with mammalian cells, both in vitro and in vivo.

With the intention of developing such a coating, molecules that simultaneously own antimicrobial, antifouling, and surface-tethering functional segments were facilely synthesized 

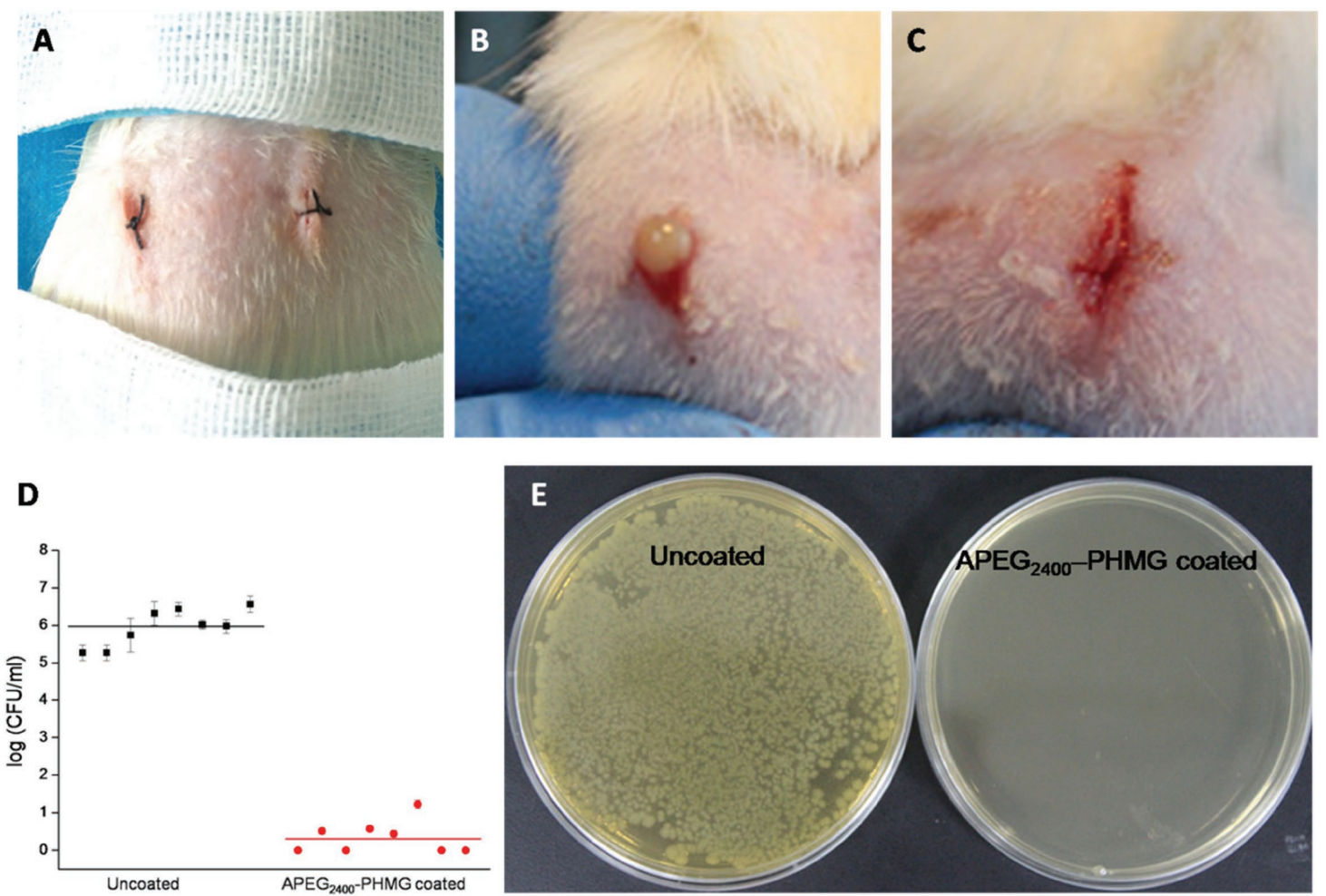

Figure 7. In vivo infection resistance assay in a rodent subcutaneous infection model: A) P. aeruginosa preseeded pristine (left) and APEG $2400^{-} \mathrm{PHMG}$ coated (right) PDMS silicone were implanted in rat's back and sutured. $5 \mathrm{~d}$ postsurgery, the observation of implantation sites: B) Visible suppuration was evident at the pristine uncoated PDMS implantation site, whereas C) PEG 2400 -PHMG-coated PDMS implantation site did not show signs of an obvious infection. D) The bacterial CFU number and E) photo of colonies from the representative pristine (uncoated) and APEG $2400-\mathrm{PHMC}_{\mathrm{C}} \mathrm{Coated}$ implants $(n=8)$. The average bacterial number from the uncoated group is $8.91 \times 10^{5}$ CFU per implant $(5.95$ log CFU), which significantly reduced by more than five magnitude to 2.19 CFU per implant ( $0.34 \mathrm{log}$ CFU) for the coated group, and four out of eight coated implants have no observable bacteria colonies.

via conjugation of APEG-OTs with PHMG. Compared to some other antimicrobial materials utilized for the developing of antimicrobial coatings, e.g., antimicrobial peptides, PHMG is an inexpensive material with excellent broad-spectrum antimicrobial activity and low mammalian toxicity. Its current price is less than $\$ 25 \mathrm{~kg}^{-1}$ (in 2016) and stock is available in tons. PEG is a well-known biocompatible polymer, which is already widely used in biomedicine. After conjugation with APEG, the synthesized APEG $_{1200 / 2400}$-PHMG block copolymers preserve potent broad-spectrum antimicrobial activity against both gramnegative/positive bacteria and fungus. The synthesis of APEGPHMG is simple, upscalable, and cost-effective, making it a promising candidate for translation to clinical applications.

Synthesized allyl-terminated PHMG oligomers were successfully grafted on the surface of plasma-activated polymeric substrates by autoclaving at $121{ }^{\circ} \mathrm{C}$ for $15 \mathrm{~min}$, forming bottlebrush-like surface coatings. Plasma is a convenient and efficient surface treatment technology, with high flexibility and applicability to nearly all kinds of polymers. In this study, argon plasma was applied to activate silicone surfaces to generate peroxide and hydroperoxide groups as surface initiators. Peroxide/ hydroperoxide groups decompose in response to ultraviolet exposure or heating and generate radicals that are capable of initiating monomers. However, the grafting reaction under normal heating in the water phase normally takes hours. ${ }^{[35,39]}$ Autoclaves are common sterilization instruments for biological labs, hospitals, and industrial plants, which are capable of achieving a maximum temperature of $121{ }^{\circ} \mathrm{C}$ under high pressure water steam. Allyl-terminated PHMG oligomers were successfully grafted on plasma activated silicone surfaces by autoclaving for $15 \mathrm{~min}$. The successful grafting was validated using XPS and AFM (Figures 2 and 3). Contact angle measurements were also conducted on PHMG-based coatings. The results indicated that the inherent hydrophobic silicone surface changed to a more hydrophilic surface owing to the successful grafting of hydrophilic oligomers. The presence and increase in length of PEG chains further increased the hydrophilicity of the surface. A minimum contact angle of $29.5^{\circ} \pm 3.5^{\circ}$ was recorded with $\mathrm{APEG}_{2400}$-PHMG coating. The hydrophilicity of PEG plays an important role in the long-term antimicrobial reusability, protein/platelet resistance, and antibiofilm properties.

The antimicrobial property of PHMG-based coatings were quantitatively assessed via a contact mode protocol. ${ }^{[20]}$ Almost complete inhibition against the three target microbes $(P$. aeruginosa, S. aureus, and F. solani) was observed. Furthermore, the long-term antimicrobial efficacy of PHMG-based coatings was evaluated via repeat challenges with high concentrations of bacteria $\left(10^{8} \mathrm{CFU} \mathrm{mL} \mathrm{m}^{-1} P\right.$. aeruginosa). Compared to the 

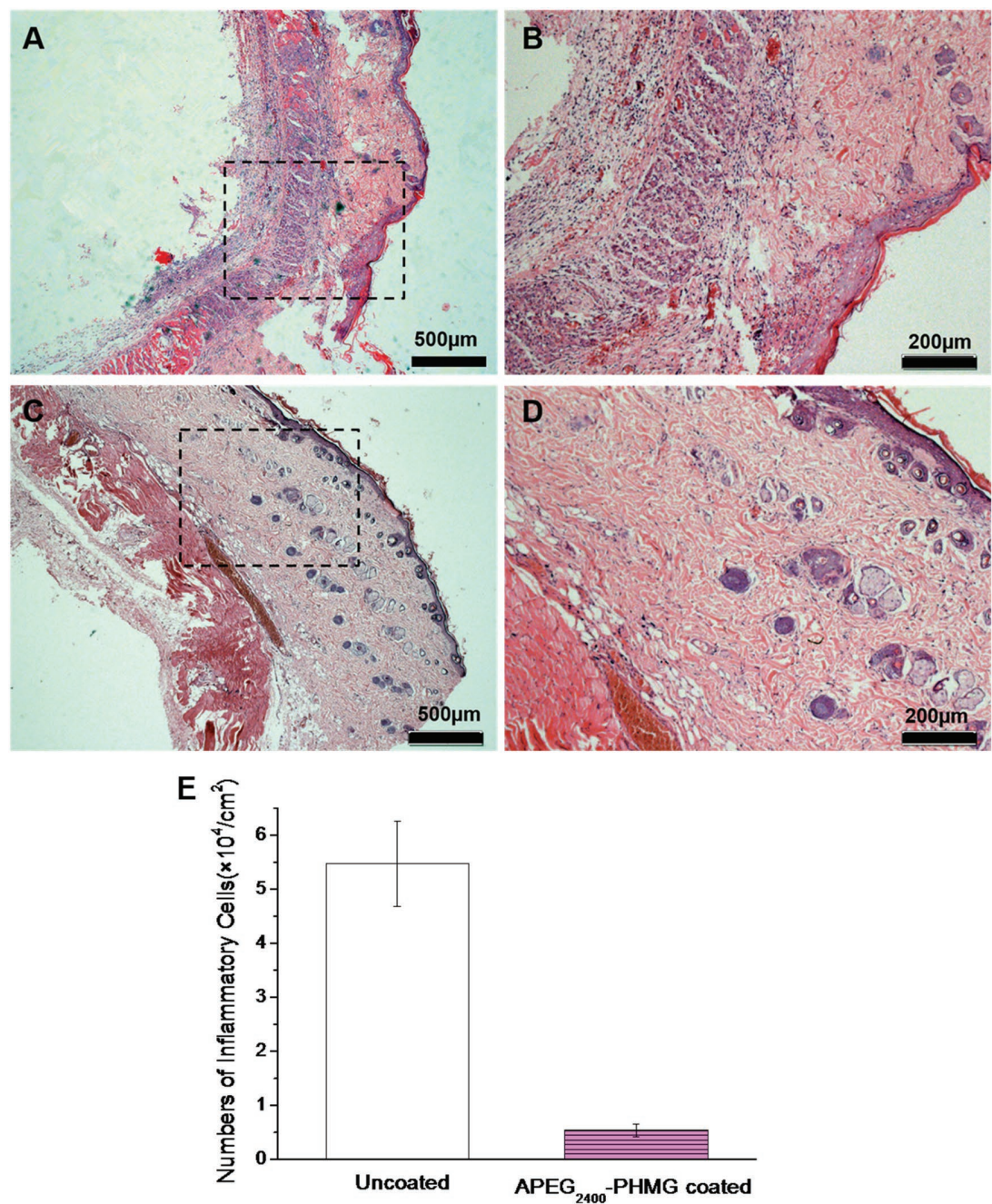

Figure 8. Representative histology images of the tissue adjacent to A,B) pristine PDMS at day 5 after implantation. Abundant inflammatory cells (stained blue color) are visible, demonstrating signs of infection at the site. Fewer inflammatory cells are visible in the tissue adjacent to C,D) APEG 2400 -PHMG-coated silicone implants. E) The number of inflammatory cells was determined as $(5.47 \pm 0.79) \times 10^{4}$ cells cm${ }^{-2}$ for uncoated silicone implants and $(0.54 \pm 0.12) \times$ $10^{4}$ cells $\mathrm{cm}^{-2}$ for $\mathrm{APEG}_{2400}$-PHMG coated silicone implants.

A-PHMG coating, which lacks antifouling PEG segments, the APEG-PHMG coating exhibited improved long-term antimicrobial efficacy. The optimal result was obtained with $\mathrm{APEG}_{2400^{-}}$ PHMG coating with longer PEG chains. Thus, PEG segments play a key role in maintaining the antimicrobial efficacy of the coating. This point was further proved in the following antifouling and antibiofilm investigations.

Fouling of the surface is a key issue for cationic antimicrobial coatings. ${ }^{[40]}$ Protein adsorption, especially of negatively charged proteins, occurs immediately when cationic antimicrobial coatings are exposed to body fluids, especially the negative charged proteins. Adsorbed proteins and other biomolecules can form a conditioning film that blocks the coating, thus potentially neutralizing its properties, including its antimicrobial efficacy. Moreover, adsorbed proteins, especially fibrinogen, can interact with integrin which exists on the surface of platelets to induce platelet adhesion and activation, and thereafter thrombus formation. ${ }^{[41]}$ Therefore, protein/platelet resistance is an essential requirement for an antimicrobial coating with in vivo efficacy. In this study, the adsorption of three proteins (BSA, lysozyme, and fibrinogen) was greatly reduced by the grafting of modified PHMG oligomers. The lowest protein adsorption was obtained on $\mathrm{APEG}_{2400}$-PHMG coating which has excellent hydrophilicity, with the reduction in the range of $88 \%-95 \%$ compared with the pristine PDMS surface. On the basis of the aforementioned contact angle measurements, it is clear that $\mathrm{APEG}_{2400}$-PHMG coating shows the lowest contact angle, which is attributed to longer PEG chains and which results in improved antifouling. Platelet adhesion was also investigated and APEG-PHMG coatings showed excellent resistance to platelets compared to that of the pristine PDMS surface. These results clearly indicate that the rationally designed APEGPHMG coatings are effective at decreasing protein and platelet adhesion.

Biofilm formation on biomaterials is the key reason of infections that must be avoided. Biofilms are extremely hard to remove and show great resistance to many kinds of conventional biocides. ${ }^{[7]}$ Microbes in biofilm are protected against the host defense and antibiotics by an extracellular polysaccharide matrix. ${ }^{[8]}$ As a result, compared to circulating bacteria, biofilms on biomedical implants are far more difficult to deracinate by using conventional drugs, and in some serious cases, a follow-up operation or removal of the infected implant is required. Therefore, it is essential for an antimicrobial coating to prevent biofilm formation. The results of LIVE/ DEAD staining indicated that APEG-PHMG coatings significantly reduced the adhesion of bacteria, thereby preventing the formation of biofilm (Figure 4). The excellent antibiofilm activity of these coatings is attributed to the simultaneous dual-functional antimicrobial and antifouling properties of the block copolymers. As shown in Figure 4C,D, although the A-PHMG coating has potent antimicrobial activity, a few live bacteria (stained green) still attached on its surface. Although antimicrobial coatings can kill bacteria that initially contacted it, dead cells and their debris could easily adsorb onto the surface and thus foul it, leading to loss of its efficacy. However, APEG-PHMG oligomers are designed with antimicrobial and antifouling functional segments in one molecule. As shown in Figure 4F-H, neither live nor dead bacteria attach onto the surface of $A P E G_{2400}-P H M G$ coatings. Hence, rationally designed APEG-PHMG coatings successfully inhibited biofilm formation in vitro.

The toxicity to mammalian cells is of utmost importance to determining the utility of a biomaterial. PHMG-based coatings were subjected to contact with mammalian erythrocytes 
(rabbit), and all three coatings tested were found to be nonhemolytic with a hemolysis rate below $2.0 \%$. The cytotoxicity of the $\mathrm{APEG}_{2400}$-PHMG coating was further characterized using MTT and LIVE/DEAD assays. When mammalian smooth muscle cells were cultured under the contacting with $\mathrm{APEG}_{2400^{-}}$ PHMG coating, cells showed good viability and proliferated during the culturing period for up to $5 \mathrm{~d}$, and were not significantly different to cells cultured with TCPS and pristine PDMS. These results demonstrate that the $\mathrm{APEG}_{2400}$-PHMG coating has selective biocidal activity toward bacteria and fungi but not mammalian cells. The membrane composition of bacteria and mammalian cells is different. The bacterial membrane consists of anionic lipids and other components, such as lipopolysaccharide or teichoic acid, which can strongly interact with cationic PHMG, whereas the outer leaflet of the mammalian cell membrane consists of zwitterionic lipids, which are less likely disrupted by cationic PHMG coatings. ${ }^{[42]}$ Therefore, the APEG ${ }_{2400^{-}}$ PHMG coating shows both potent antimicrobial efficacy and low mammalian cell cytotoxicity.

Considerable research on antimicrobial coatings has been published in recent years, but the majority of these studies lack in vivo characterization of the properties and performance of the coatings. Our $\mathrm{APEG}_{2400}$-PHMG coating shows excellent in vitro antimicrobial, antiprotein/platelet adhesion, and antibiofilm properties, as well as nonhemolytic/cytotoxic properties. Its in vivo activity was also studied in rats with a biomaterial-associated $P$. aeruginosa infection model. The results of implanting uncoated silicone confirmed that $P$. aeruginosa preseeded onto implants could successfully infect surrounding tissue after implantation. At $5 \mathrm{~d}$ after implantation, large numbers $\left(8.91 \times 10^{5} \mathrm{CFU}\right.$ in average) of bacteria were observed to grow on uncoated implants. In contrast, $\mathrm{APEG}_{2400^{-}}$ PHMG coated implants significantly reduced the number of bacteria that was found on the surface of the implant. Four out of eight implants harbored no observable P. aeruginosa colonies and the other four implants only harbored low amounts of bacteria. $\mathrm{APEG}_{2400}$-PHMG coating reduced the bacterial number by more than five orders of magnitude, and prevented the biomaterial-associated infection in this rodent model. Histological study of H\&E-stained tissue sections that surrounded the implant further confirmed hallmarks of inflammation in the uncoated implant group and reduced inflammation in the $\mathrm{APEG}_{2400}$-PHMG coated group.

\section{Conclusion}

In this study, we successfully engineered a novel synthetic antimicrobial and antifouling dual-functional APEG-PHMG block copolymer, whose preparation is facile, upscalable, and inexpensive. We also developed a simple plasma/autoclavingassisted method to easily graft APEG-PHMG oligomers on polymeric substrates. Autoclaving-induced surface grafting polymerization formed a bottlebrush-like surface coating within $15 \mathrm{~min}$. Surface characterization studies, including contact angle measurements, XPS, and AFM, confirmed successful coating on silicone surfaces. The APEG $1200 / 2400$-PHMG coatings exhibited potent broad-spectrum and reusable antimicrobial activity, protein/platelet-resistance, and antibiofilm properties, which were superior to that of the A-PHMG coating that lacked antifouling segments. $\mathrm{APEG}_{2400}$-PHMG coating has optimal antimicrobial and antifouling efficacy, and is nonhemolytic and nontoxic to mammalian cells. More importantly, $\mathrm{APEG}_{2400^{-}}$ PHMG coating successfully inhibited bacterial growth and prevented implant-associated infection caused by $P$. aeruginosa in an animal model. These results indicate that APEG-PHMG dual-functional diblock copolymer is a promising candidate to prevent bacterial colonization and biofilm formation on biomedical implants.

\section{Experimental Section}

Materials: Polyhexamethylene guanidine hydrochloride was purchased from Wonda Science (USA). APEG $\left(M_{n}=1200\right.$ and $\left.2400 \mathrm{Da}\right)$ were purchased from Maya Reagent, China. AGE, TsCl, BSA, fibrinogen, lysozyme, Dimethyl Sulphoxide (DMSO), and phosphate buffer saline (PBS) were purchased from Sigma-Aldrich. Sylgard 184 silicone elastomer kit was purchased from Dow Corning. Luria-Bertani (LB) agar, Mueller-Hinton (MH) broth, and Yeast-Malt (YM) broth were purchased from Oxoid, UK. BCA protein kit, FITC-labeled BSA, and LIVE/DEAD Baclight kit was purchased from Thermo Fisher, USA.

Synthesis and Characterization of A-PHMG and APEG-PHMC Oligomers: A-PHMG was synthesized following a modified method reported by Wei et al. ${ }^{[29]}$ Briefly, a given mass of PHMC was dissolved in DMSO to obtain a solution ( $38.0 \mathrm{wt} \%$ ) in a flask with stirring at room temperature. The temperature of system was raised to $60{ }^{\circ} \mathrm{C}$ and kept for $30 \mathrm{~min}$, following with the addition of AGE at the same molar mass with PHMG. The reaction system was kept at $60^{\circ} \mathrm{C}$ with stirring for $2 \mathrm{~d}$. Then, to remove unreacted $A G E$ and solvent, the reaction mixture was repeatedly purified via precipitation/dissolution in acetone/methanol thrice. The purified product was obtained after drying in vacuum at room temperature for $12 \mathrm{~h}$. The synthesis scheme is shown in Scheme 1A.

APEG-OTs were synthesized following a modified method described by Shi et al. ${ }^{[43]}$ Typically, $0.056 \mathrm{~mol}$ of APEG was dissolved in $10 \mathrm{~mL}$ of anhydrous pyridine in a flask with stirring. The reaction system was cooled down with ice bath, then $0.102 \mathrm{~mol} \mathrm{TsCl}$ was added and the mixture was stirred for $5 \mathrm{~h}$ with the protection of nitrogen. After that, $60 \mathrm{~mL}$ of $\mathrm{CH}_{2} \mathrm{Cl}_{2}$ was added and the reaction system was continually stirred for $30 \mathrm{~h}$ at room temperature. Thereafter, another $60 \mathrm{~mL}$ of $\mathrm{CH}_{2} \mathrm{Cl}_{2}$ was added and the reaction mixture was successively washed $2100 \mathrm{~mL}$ of $\mathrm{H}_{2} \mathrm{O}, 100 \mathrm{~mL}$ of $\mathrm{HCl}(10 \mathrm{M}), 100 \mathrm{~mL}$ of saturated $\mathrm{NaHCO}_{3}$ solution, and the organic phase was collected and dried using $\mathrm{MgSO}_{4}$ for further use. The organic reaction mixture was rotary evaporated to remove the solvents, and the final product was obtained in a colorless liquid form. The synthesis scheme is shown in Scheme 1A.

The modified APEG-PHMG oligomer was obtained as follows: first, PHMG was dissolved in methanol with $20.0 \mathrm{wt} \%$, then a certain amount of $\mathrm{K}_{2} \mathrm{CO}_{3}(4 \mathrm{eq})$ was added in the solution, stirring at room temperature and $\mathrm{N}_{2}$ atmosphere. Subsequently, the mixture was heated to $65^{\circ} \mathrm{C}$ and refluxed for $30 \mathrm{~min}$. Then, APEG-OTs were added into the mixture and (feeding molar ratio of PHMG to APEG-OTs was 1.2) stirred for $24 \mathrm{~h}$ at $65^{\circ} \mathrm{C}$. The crude product solutions were mixed with diluted hydrochloric acid $(0.5 \mathrm{M})$ to obtain a neutral mixture. Finally, the products were dialyzed for $5 \mathrm{~d}$, then concentrated under rotary evaporation and freeze dried for further studies.

${ }^{1} \mathrm{H}$ NMR spectra of pristine PHMG and modified PHMG were determined using a Bruker spectrometer Ascend-400 with DMSO- $\mathrm{d}_{6}$ or $\mathrm{D}_{2} \mathrm{O}$ as solvents.

MIC Assay: P. aeruginosa (ATCC 27853), S. aureus (ATCC 6538), and F. solani (ATCC 36031) were utilized as target pathogens and all obtained from ATCC. Minimum inhibitory concentrations of PHMG and modified PHMG oligomers were performed against $P$. aeruginosa, $S$. aureus, and F. solani spore by using a broth microdilution protocol. ${ }^{[44]}$ In short, $100 \mu \mathrm{L}$ pristine PHMG and modified PHMG oligomers were added in a 
96-well microplate with at different concentrations $\left(1.2-2500 \mu \mathrm{g} \mathrm{mL} \mathrm{L}^{-1}\right)$.

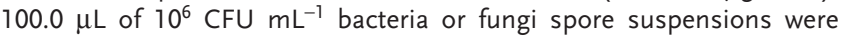
then added to the wells to allow the final microbial concentration to be $5 \times 10^{5} \mathrm{CFU} \mathrm{mL}$. The plate was placed in an incubator at $37^{\circ} \mathrm{C}$ for $18 \mathrm{~h}\left(28^{\circ} \mathrm{C}\right.$ and $36 \mathrm{~h}$ for Fungi). The MIC was determined to be the lowest concentration that no visible microbial growth could be detected at $600 \mathrm{~nm}$ with a microplate reader (SpectraMax, Molecular Devices).

Preparation of A-PHMG and APEG-PHMG Coatings on Silicone Surface: PDMS silicone was prepared following the manufacturer's instructions using 184 elastomer kit (Dow Corning, USA), then rinsed in $n$-hexane for $24 \mathrm{~h}$ to remove the unreacted monomer. Then, the silicone slides were taken out and vacuum dried. The silicone slides were pretreated with argon plasma (FEMTO, Ebhausen, Germany) for 5 min (50 W, $25 \mathrm{sccm}$ ). After this, PDMS slides were immersed in 5\% A-PHMG or APEG-PHMG solution in vial bottles, and then autoclaved at $121^{\circ} \mathrm{C}$ for 15 min (Zealway GI54DWS). Thus, the A-PHMG or APEG-PHMG bottlebrush coatings were grafted on silicone surface. Prior to other characterizations and tests, the grafted PDMS slides were washed in deionized water and ethanol under sonication for $15 \mathrm{~min}$, respectively, to remove the ungrafted oligomers.

Surface Characterization of the Coatings: Static water contact angle measurements were determined using a goniometer equipped with an imaging system (SL200KB, Kino, USA). $5.0 \mu \mathrm{L}$ of water droplets were injected onto the pristine or modified silicone surfaces the images were recorded. The contact angle was quantitatively determined using CAST V2.20 software. The surface composition of pristine and modified silicone was also determined by XPS (Thermo Fisher Scientific, USA). The surface morphology of pristine and PHMG oligomer modified PDMS was imaged using AFM (Cypher ES, Asylum Research, USA) at tapping mode. The grafting thickness was also determined using AFM on a partial grafted sample following a method Rayatpisheh et al. reported. [39] Briefly, for partial grafting with a sharp boundary on the surface of a PDMS slide, another PDMS slide was placed on the sample to cover half of the surface before argon plasma activation. The subsequent grafting procedure was as normal as described in the previous section. The measurement was carried out on three independently prepared samples.

Antimicrobial Activity Determination of Coatings: The antimicrobial activity of the PHMG oligomer coated PDMS slides was determined using a reported protocol. ${ }^{[20]}$ Prior to the microbiological test, the slides were sterilized using $70 \%$ ethanol and washed with PBS then dried in biosafety cabinet. Briefly, P. aeruginosa and S. aureus were cultivated in LB medium overnight at $37.0^{\circ} \mathrm{C}$, then recultivated in fresh medium and grown to optical density $(\mathrm{OD})_{600}=0.5$. F. solani was cultivated on an $\mathrm{YM}$ agar slope for $72 \mathrm{~h}$ at $28^{\circ} \mathrm{C}$, then its spore was harvested by adding PBS into the slope and shaking over a vortex mixer. The concentrations of

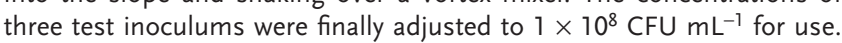
$10.0 \mu \mathrm{L}$ of the bacteria or fungal spore suspension was then spread over each modified-PHMG coating PDMS slides, which were covered with another slide and softly pressed to spread the inoculums over the whole surface. The inoculated slides were cultured at $37.0{ }^{\circ} \mathrm{C}$ for $1 \mathrm{~h}$. Then, $2 \mathrm{~mL}$ PBS was added into the $35 \mathrm{~mm}$ Petri dishes containing the testing slides, to wash out the survived microbe. And the bacteria or fungus suspensions were plated for CFU counts. This test was repeated with at least triplicate samples, pristine PDMS was used as control group. The kill percent ratio was calculated by the following formula given in Equation (1)

Kill ratio $=\frac{\mathrm{CPU}(\text { control }- \text { treated })}{\mathrm{CPF}(\text { control })} \times 100 \%$

Protein Fouling Assay: The protein adsorption on the surface was determined using BCA assay. ${ }^{[45]}$ The standard calibration curves of BSA, fibrinogen, and lysozyme were prepared following the recommended protocol from the manufacturer first. Pristine and modified-PHMG coated PDMS slides of size $2 \times 2 \mathrm{~cm}^{2}$ were rinsed in PBS buffer $(\mathrm{pH}$ 7.4) for $12 \mathrm{~h}$, and then immersed in pure BSA, fibrinogen, and lysozyme protein solutions ( $5 \mathrm{mg} \mathrm{mL}^{-1}$ in PBS) at $37{ }^{\circ} \mathrm{C}$ for $24 \mathrm{~h}$. After this, the films were washed using PBS and deionized water thrice, respectively.
The films were then put into a clean 12-well plate, and added with $500 \mu \mathrm{L}$ of $2.0 \mathrm{wt} \%$ SDS aqueous solution in each well, subjected to shaking for $2 \mathrm{~h}$, and sonicated for $2 \mathrm{~h}$ at room temperature to remove the absorbed protein from the films. $100 \mu \mathrm{L}$ of each protein washing solutions were transferred to a new clean 96-well plate, and then another $100 \mu \mathrm{L}$ of the BCA assay reagent was added, mixed for $3 \mathrm{~min}$ on a plate shaker. After incubation at $60^{\circ} \mathrm{C}$ for $1 \mathrm{~h}$, the absorbance of the protein concentration in the washing solution was measured at $560 \mathrm{~nm}$ with SpectraMax paradigm multimode detection platform (Molecular Devices, USA). The adsorbed protein amount was determined from the standard calibration curve. The protein adsorption on the surface was also observed under fluorescence microscope using fluorescein isothiocyanate labeled BSA. After a thorough rinsing with PBS, the pristine and modifiedPHMC coated PDMS slides were immersed in a solution containing $5 \mathrm{mg} \mathrm{mL}^{-1}$ of BSA-FITC for $24 \mathrm{~h}$ and then washed with PBS to remove the unattached proteins. The fluorescence image of the surfaces was captured using an inverted fluorescence microscope (IX53, Olympus, Japan).

Reusable Antimicrobial Activity of Coatings: To explore reusable antimicrobial activity of the modified-PHMG coated PDMS slides after aforementioned test (Section Antimicrobial Activity Determination of Coatings in the Experimental Section), the used PDMS slides were washed and sterilized with $70 \%$ ethanol for $30 \mathrm{~min}$, then washed with sterile $\mathrm{ddH}_{2} \mathrm{O}$ several times. Afterward, these slides were dried in the air and repeat challenged with $P$. aeruginosa up to ten times, following the method described in the previous section.

Antibiofilm Activity of Coatings: P. aeruginosa was cultured overnight and then diluted to a final concentration of $1 \times 10^{8} \mathrm{CFU} \mathrm{mL}^{-1}$ in $\mathrm{MH}$ broth. Pristine PDMS, A-PHMG, and APEG $1200 / 2400^{-}$PHMG coated $^{-}$ PDMS slides were submersed in $2 \mathrm{~mL}$ of the bacteria seeded broth and cultured for $5 \mathrm{~d}$. After that, the slides were took out and rinsed in PBS to remove the unattached planktonic bacteria. The biofilm forming on the slides was observed with an inverted fluorescence microscope (IX53, Olympus, Japan) after being stained by the LIVE/DEAD Baclight kit (Thermo Fisher, USA).

Platelet Adhesion Assay: The platelet adhesion on the surfaces of modified PHMG coated PDMS was studied following a previously reported protocol.[46] Platelet-rich plasma (PRP) was collected by centrifuging rabbit fresh blood (obtained from the Xi'an jiaotong University Medical College, containing heparin sodium as anticoagulant) at $400 \times g$ for $15 \mathrm{~min}$. The slides were first rinsed with PBS for $1 \mathrm{~h}$ at $37^{\circ} \mathrm{C}$. After that, PBS solution was removed and $1 \mathrm{~mL}$ of PRP was added. After incubation at $37{ }^{\circ} \mathrm{C}$ for $2 \mathrm{~h}$, the PRP was removed. The platelet adhered slides were rinsed using PBS thrice, then fixed using $2.5 \mathrm{wt} \%$ glutaraldehyde at $4{ }^{\circ} \mathrm{C}$ overnight. The specimen was then passed through a series of graded alcohol solutions (25\%-100\%) to be dehydrated. Pristine PDMS was used as control group. The platelet adhesion on the slides was investigated with a FESEM (FEI Quant 250) and the number of adhered platelets were also quantitatively counted with three independent prepared samples.

Hemolysis Assay: The hemolysis assay was performed following a method referred to Wang et al. reported. ${ }^{[47]} 2 \mathrm{~mL}$ of fresh rabbit red blood cells (RBCs) were collected, washed with Tris buffer thrice, then centrifuged at $400 \times \mathrm{g}$ for $10 \mathrm{~min}$ and diluted to a final RBC concentration of $5.0 \%(\mathrm{v} / \mathrm{v})$ in Tris buffer. The modified PHMG coated PDMS were submerged in $2 \mathrm{~mL}$ of RBC suspension and incubated at $37^{\circ} \mathrm{C}$ for $1 \mathrm{~h}$, with shaking at $100 \mathrm{rpm}$. After incubation with the different samples, the RBC suspensions were collected and centrifuged at $400 \times g$ for $10 \mathrm{~min}$. The supernatant was transferred to a clean 96 -well plate and the absorbance of released hemoglobin was determined at $540 \mathrm{~nm}$ using a microplate reader (SpectraMax, Molecular Devices, USA). 0\% and $100 \%$ hemolysis controls were obtained by suspending RBC in Tris buffer and $0.1 \%$ Triton $X$, respectively.

In Vitro Cytotoxicity Assay: The cytotoxicity of PDMS-g-APEG $2400^{-P H M G}$ coating was studied following a contact mode protocol using human aorta smooth muscle cells, CC-2571 (Lonza, USA). ${ }^{[20]}$ The pristine and APEG $_{2400}$-PHMG coated PDMS slides were cut into $1 \mathrm{~cm}$ diameter disks and sterilized with $70 \%$ ethanol, followed by rinsing with sterilized PBS. 
Smooth muscle cells $\left(0.5 \times 10^{5}\right.$ cells $\left.\mathrm{cm}^{-2}\right)$ were cultured in 24-well culture plate using Dulbecco's Modified Eagle's Medium (Thermo Fisher, USA) supplemented with $10 \%$ fetal bovine serum (Hyclone, USA). After $6 \mathrm{~h}$ for cell attachment on the culturing plate, the presterilized slides were carefully transferred to the wells containing SMCs, ensuring the coating side was faced to the cells. The plate containing cells and slides was cultured for $5 \mathrm{~d}$, and the culture medium was changed every $2 \mathrm{~d}$. On the 1st, 3rd, and 5th day, the viability of the cells contacting with PDMSg-APEG 2400 -PHMG and untreated PDMS slides were determined with MTT and LIVE/DEAD assays. MTT assay was implemented following the protocol described by Qi et al. ${ }^{[48]}$ The cells were also stained using LIVE/DEAD cell viability kit (Thermo Fisher) and then examined with an inverted fluorescence microscope (IX53, Olympus, Japan).

In Vivo Rodent Subcutaneous Infection Model: The protocol was approved by the Animal Ethical, Care and Use Committee of the Xi'an Jiaotong University. The immune competent Sprague-Dawley female rats (Harlan, Horst, Netherlands), which aged seven to nine weeks weighing 200-220 g were applied. The rats were living in individually ventilated cages (IVCs) and were provided with food and water as required.

$\mathrm{APEG}_{2400}$-PHMG coated and pristine uncoated silicone specimens were used for implants in this study. The two kinds of implants were first sterilized by rinsing with $70 \%$ ethanol for $30 \mathrm{~min}$, then rinsed with sterilized PBS and dried in biosafety cabinet. The dried slides were preseeded with $25 \mu \mathrm{L}$ of inoculums containing $10^{9} \mathrm{CFU} \mathrm{\textrm {mL } ^ { - 1 }}$ $P$. aeruginosa and air-dried in biosafety cabinet $5 \mathrm{~min}$ before the implantation. ${ }^{[49]}$ Eight animals were used in this test.

Prior to the surgical procedure, rats were anesthetized with $10 \%$ chloral hydrate injected in a laminar flow cabinet. The backs of the rats were shaved and sterilized with iodophor disinfection solution. An incision of $0.5 \mathrm{~cm}$ was done $1 \mathrm{~cm}$ lateral to the spine on each side. The silicone specimens were implanted subcutaneously and the incisions were closed with a single 0/6 vicryl stitch subsequently. After surgery, rats were living individually in IVCs.

At $5 \mathrm{~d}$ postimplantation, rats were anesthetized with $10 \%$ chloral hydrate injected $15 \mathrm{~min}$ before taking out the implants. The incisions were cut off and these implanted samples were taken out by sterile probe forceps, then they were put into sterile tube with $1 \mathrm{~mL}$ PBS buffer, respectively. The implants were sonicated for $10 \mathrm{~min}$ to detach the adhered bacteria on the surface, and the CFUs were determined by tenfold dilution plating. Meanwhile, the infectious statuses of these incisions were investigated.

Portions of epidermal tissues were sampled from these treated rats, and fixed in $10 \%$ neutral buffered formalin. Then, samples were wax-embedded and sectioned for H\&E staining according to standard histological protocols at the Medical School in the Xi'an Jiaotong University.

Statistical Analysis: All the quantitative data are presented as mean \pm standard deviation unless otherwise specified. Significance was taken as $p<0.05$ unless otherwise stated.

\section{Supporting Information}

Supporting Information is available from the Wiley Online Library or from the author.

\section{Acknowledgements}

This work was funded and supported by the Natural Science Foundation of China (No. 51403173), the Natural Science Basic Research Plan in Shaanxi Province of China (No. 2015JQ5139), and the Fundamental Research Funds for the Central Universities of China. The authors thank Prof. Yongquan Qu and Prof. Yaodong Yang (Xi'an Jiaotong University, China) for their kind assistance in plasma and AFM operation.

Received: October 16, 2016

Revised: December 25, 2016

Published online: January 27, 2017
[1] D. W. Grainger, H. C. van der Mei, P. C. Jutte, J. J. A. M. van den Dungen, M. J. Schultz, B. F. A. M. van der Laan, S. A. J. Zaat, H. J. Busscher, Biomaterials 2013, 34, 9237.

[2] A.-L. Smith, Australas. Phys. Eng. Sci. Med. 2011, 34, 431.

[3] H. J. Busscher, H. C. van der Mei, G. Subbiahdoss, P. C. Jutte, J. van den Dungen, S. A. J. Zaat, M. J. Schultz, D. W. Grainger, Sci. Transl. Med. 2012, 4, 153rv10.

[4] a) P. Cernohorsky, M. M. Reijnen, I. F. Tielliu, S. M. van Sterkenburg, J. J. van den Dungen, C. J. Zeebregts, J. Vasc. Surg. 2011, 54, 327; b) D. Campoccia, L. Montanaro, C. R. Arciola, Biomaterials 2006, 27, 2331.

[5] G. M. Viola, J. Rosenblatt, I. I. Raad, Adv. Drug Delivery Rev. 2016, DOI: 10.1016/j.addr.2016.07.011.

[6] D. M. Siddiq, R. O. Darouiche, Nat. Rev. Urol. 2012, 9, 305.

[7] L. Hall-Stoodley, J. W. Costerton, P. Stoodley, Nat. Rev. Urol. 2004, 2, 95.

[8] D. Davies, Nat. Rev. Drug Discovery 2003, 2, 114.

[9] R. Laxminarayan, A. Duse, C. Wattal, A. K. M. Zaidi, H. F. L. Wertheim, N. Sumpradit, E. Vlieghe, G. L. Hara, I. M. Gould, H. Goossens, C. Greko, A. D. So, M. Bigdeli, G. Tomson, W. Woodhouse, E. Ombaka, A. Q. Peralta, F. N. Qamar, F. Mir, S. Kariuki, Z. A. Bhutta, A. Coates, R. Bergstrom, G. D. Wright, E. D. Brown, O. Cars, Lancet Infect. Dis. 2013, 13, 1057.

[10] N. Du, H. Wang, J. Q. Niu, H. L. Sun, M. J. Chen, B. J. Hu, Y. S. Yu, Z. Y. Sun, Y. Z. Chu, Chin. J. Lab. Med. 2007, 30, 499.

[11] a) J. Yatvin, J. Gao, J. Locklin, Chem. Commun. 2014, 50, 9433; b) M. Salwiczek, Y. Qu, J. Gardiner, R. A. Strugnell, T. Lithgow, K. M. McLean, H. Thissen, Trends Biotechnol. 2014, 32, 82; c) F. Costa, I. F. Carvalho, R. C. Montelaro, P. Gomes, M. C. L. Martins, Acta Biomater. 2011, 7, 1431.

[12] a) B. R. Coad, S. E. Kidd, D. H. Ellis, H. J. Griesser, Biotechnol. Adv. 2014, 32, 296; b) Y. Lu, Z. G. Yue, W. Wang, Z. Q. Cao, Front. Chem. Sci. Eng. 2015, 9, 324.

[13] a) N. Hadjesfandiari, K. Yu, Y. Mei, J. N. Kizhakkedathu, J. Mater. Chem. B 2014, 2, 4968; b) A. Muñoz-Bonilla, M. Fernández-García, Eur. Polym. J. 2015, 65, 46

[14] G. Gao, D. Lange, K. Hilpert, J. Kindrachuk, Y. Zou, J. T. J. Cheng, M. Kazemzadeh-Narbat, K. Yu, R. Wang, S. K. Straus, D. E. Brooks, B. H. Chew, R. E. W. Hancock, J. N. Kizhakkedathu, Biomaterials 2011, 32, 3899.

[15] G. T. Qin, A. Lopez, C. Santos, A. M. McDermott, C. Z. Cai, Biomater. Sci. 2015, 3, 771.

[16] W. J. Yang, T. Cai, K.-G. Neoh, E.-T. Kang, G. H. Dickinson, S. L.-M. Teo, D. Rittschof, Langmuir 2011, 27, 7065.

[17] C. Yang, X. Ding, R. J. Ono, H. Lee, L. Y. Hsu, Y. W. Tong, J. Hedrick, Y. Y. Yang, Adv. Mater. 2014, 26, 7346.

[18] B. Li, B. Yu, Q. Ye, F. Zhou, Acc. Chem. Res. 2015, 48, 229.

[19] a) C. Zhou, P. Li, X. Qi, A. R. M. Sharif, Y. F. Poon, Y. Cao, M. W. Chang, S. S. J. Leong, M. B. Chan-Park, Biomaterials 2011, 32, 2704; b) X. Li, P. Li, R. Saravanan, A. Basu, B. Mishra, S. H. Lim, X. D. Su, P. A. Tambyah, S. S. J. Leong, Acta Biomater. 2014, 10, 258.

[20] P. Li, Y. F. Poon, W. F. Li, H. Y. Zhu, S. H. Yeap, Y. Cao, X. B. Qi, C. C. Zhou, M. Lamrani, R. W. Beuerman, E. T. Kang, Y. G. Mu, C. M. Li, M. W. Chang, S. S. J. Leong, M. B. Chan-Park, Nat. Mater. 2011, 10, 149.

[21] S. Rogalsky, J. F. Bardeau, H. Wu, L. Lyoshina, O. Bulko, O. Tarasyuk, S. Makhno, T. Cherniavska, Y. Kyselov, J. H. Koo, J. Mater. Sci. 2016, 51, 7716.

[22] a) J. Kusnetsov, A. Tulkki, H. Ahonen, P. Martikainen, J. Appl. Microbiol. 1997, 82, 763; b) O. Kukharenko, J.-F. Bardeau, I. Zaets, L. Ovcharenko, O. Tarasyuk, S. Porhyn, I. Mischenko, A. Vovk, S. Rogalsky, N. Kozyrovska, Eur. Polym. J. 2014, 60, 247.

[23] D. Wei, Q. Ma, Y. Guan, F. Hu, A. Zheng, X. Zhang, Z. Teng, H. Jiang, Mater. Sci. Eng., C 2009, 29, 1776. 
[24] T. Buchberger, M. Himmelsbach, W. Buchberger, J. Chromatogr. A 2013, 1318, 22.

[25] A. Muñoz-Bonilla, M. Fernández-García, Prog. Polym. Sci. 2012, 37, 281.

[26] W. Hartleb, J. S. Saar, P. Zou, K. Lienkamp, Macromol. Chem. Phys. 2016, 217, 225

[27] C. Wu, Chinese J. Polym. Sci. 2014, 32, 1575.

[28] N. Karousis, N. Tagmatarchis, D. Tasis, Chem. Rev. 2010, 110, 5366.

[29] D. Wei, R. Zhou, Y. Guan, A. Zheng, Y. Zhang, J. Appl. Polym. Sci. 2013, 127, 666 .

[30] M. Suzuki, A. Kishida, H. Iwata, Y. Ikada, Macromolecules 1986, 19, 1804.

[31] B. D. Ratner, S. J. Bryant, Annu. Rev. Biomed. Eng. 2004, 6, 41.

[32] K. Hori, S. Matsumoto, Biochem. Eng. J. 2010, 48, 424.

[33] a) S. Noimark, J. Weiner, N. Noor, E. Allan, C. K. Williams, M. S. P. Shaffer, I. P. Parkin, Adv. Funct. Mater. 2015, 25, 1367; b) D. L. Williams, B. S. Haymond, J. P. Beck, P. B. Savage, V. Chaudhary, R. T. Epperson, B. Kawaguchi, R. D. Bloebaum, Biomaterials 2012, 33, 8641.

[34] T. Segura, A. M. Puga, G. Burillo, J. Llovo, G. Brackman, T. Coenye, A. Concheiro, C. Alvarez-Lorenzo, Biomacromolecules 2014, 15, 1860.

[35] M. Li, K.-G. Neoh, E.-T. Kang, T. Lau, E. Chiong, Adv. Funct. Mater. 2014, 24, 1631.

[36] I. Fundeanu, H. C. van der Mei, A. J. Schouten, H. J. Busscher, Colloids Surf., B 2008, 64, 297.

[37] a) Z. X. Voo, M. Khan, Q. Xu, K. Narayanan, B. W. J. Ng, R. B. Ahmad, J. L. Hedrick, Y. Y. Yang, Polym. Chem. 2016, 7, 656; b) X. Ding, C. Yang, T. P. Lim, L. Y. Hsu, A. C. Engler, J. L. Hedrick, Y. Y. Yang, Biomaterials 2012, 33, 6593.

[38] F. Siedenbiedel, J. C. Tiller, Polymers 2012, 4, 46.

[39] S. Rayatpisheh, P. Li, M. B. Chan-Park, Macromol. Biosci. 2012, 12, 937.

[40] P. Zou, W. Hartleb, K. Lienkamp, J. Mater. Chem. 2012, 22, 19579.

[41] J. Grunkemeier, W. Tsai, C. McFarland, T. Horbett, Biomaterials 2000, 21, 2243.

[42] G. J. Gabriel, A. Som, A. E. Madkour, T. Eren, G. N. Tew, Mater. Sci. Eng., $R$ 2007, 57, 28.

[43] X. Shi, L. Tan, J. Xing, F. Cao, L. Chen, Z. Luo, Y. Wang, J. Appl. Polym. Sci. 2013, 128, 1995.

[44] P. Li, C. Zhou, S. Rayatpisheh, K. Ye, Y. F. Poon, P. T. Hammond, H. Duan, M. B. Chan-Park, Adv. Mater. 2012, 24, 4130.

[45] R. E. Brown, K. L. Jarvis, K. J. Hyland, Anal. Biochem. 1989, 180 136.

[46] J. Gu, Y. Su, P. Liu, P. Li, P. Yang, ACS Appl. Mater. Interfaces 2016 DOI: $10.1021 /$ acsami.6b13552.

[47] Y. Wang, A. G. El-Deen, P. Li, B. H. L. Oh, Z. Guo, M. M. Khin, Y. S. Vikhe, J. Wang, R. G. Hu, R. M. Boom, K. A. Kline, D. L. Becker, H. Duan, M. B. Chan-Park, ACS Nano 2015, 9, 10142.

[48] X. Qi, C. Zhou, P. Li, W. Xu, Y. Cao, H. Ling, W. N. Chen, C. M. Li, R. Xu, M. Lamrani, Y. Mu, S. S. J. Leong, M. W. Chang, M. B. Chan-Park, Biochem. Biophys. Res. Commun. 2010, 398, 594.

[49] M. Riool, L. de Boer, V. Jaspers, C. M. van der Loos, W. J. van Wamel, G. Wu, P. H. Kwakman, S. A. Zaat, Acta Biomater. 2014, 10, 5202. 